ISSN: 0213-2079 - ISSN electrónico: 2386-3889

DOI: https://doi.org/10.14201/shhmo2016382425466

\title{
INFORMACIÓN Y REPUTACIÓN EN EL SIGLO XVII: LA CONSTRUCCIÓN DE LA CONFIANZA EN REDES SOCIALES DE HOMBRES DE NEGOCIOS PORTUGUESES
}

\section{Information and Reputation in the 17th Century: Establish- ing Trust in the Social Networks of Portuguese Businessmen}

\author{
Álvaro SÁNCHEZ DURÁN \\ Universidad Autónoma de Madrid \\ Correo-e: alvaro.sanchezd@uam.es
}

RESUMEN: El presente trabajo examina el rol desempeñado durante el periodo moderno por una serie de prácticas socioculturales asociadas a la articulación de la confianza interpersonal en el mundo de los negocios. Para dicho fin se recurre al análisis cualitativo de las interacciones sociales producidas en el seno de las redes egocentradas de cinco hombres de negocios portugueses establecidos en Madrid en las décadas centrales del siglo XVII, llevado a cabo mediante la consulta de su correspondencia epistolar. Las cartas posibilitarán evaluar el papel ejercido por la transmisión de información y por una serie de valores culturales en la forja de la confianza. Del mismo modo, se comprobará la importancia crucial de la reputación personal como valoración subjetiva de las aptitudes de los actores económicos y cómo dichas valoraciones se gestaban mediante interacciones epistolares.

* Este artículo se inscribe en el Proyecto de Investigación Nuevas perspectivas de bistoria social en la ciudad de Madrid y sus áreas de influencia en la época moderna (HAR2014-53298C2-2-P), financiado por el Ministerio de Economía y Competitividad. La realización del mismo ha sido posible gracias a una ayuda del Programa de Formación de Profesorado Universitario (FPU 2013), Ministerio de Educación, Cultura y Deporte.

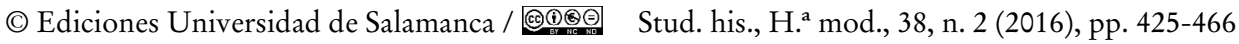


Finalmente, se atenderá al recurso a las reputaciones como criterio de selección o reclutamiento de agentes.

Palabras clave: Confianza; Hombres de negocios; Redes; Cartas; Información; Reputación.

ABSTRACT: This paper examines the role played by diverse social and cultural practices in the establishment of interpersonal trust during the Early Modern period. Based on qualitative analysis of social interactions within the ego-centered networks of five Portuguese businessmen living in Madrid during the $17^{\text {th }}$ Century, studied thanks to their epistolary correspondence. Letters allow historians to assess the role of the transmission of information and diverse cultural values in forging trust. Moreover, they also document the crucial importance of personal reputation as a form of subjective valuation of the aptitudes of economic actors, and how these assessments were produced thanks to epistolary interactions. Finally, attention is drawn to how reputations served as a means of selecting and recruiting agents.

Key words: Trust; Businessmen; Networks; Letters; Information; Reputation.

\section{INTRODUCCIÓN: DEBATES EN TORNO A LA COOPERACIÓN Y LA CONFIANZA}

Durante las últimas décadas el estudio de los fundamentos de la cooperación económica ha despertado un gran interés tanto en el campo de la historia económica como en el de la sociología. Como consecuencia de ello conceptos como los de «confianza», «reputación», «capital social», «cálculo racional» o "coalición» han gozado de una enorme profusión en unas investigaciones que en ocasiones han tratado de probar sus hipótesis mediante ejemplos empíricos de sociedades del pasado. Esa es la razón de que tarde o temprano la disciplina histórica se haya visto forzada a dirigir su punto de atención a estas cuestiones, sobre todo en relación con el estudio de las interacciones mercantiles. Para el caso del periodo moderno se trata de una temática en pleno apogeo desde la década de 1990, al calor del desarrollo o consolidación de nuevas corrientes historiográficas como la Atlantic History y la Global History, así como de la aplicación de nuevas metodologías como el análisis de redes sociales. Como consecuencia, han proliferado trabajos que han abordado la problemática de los basamentos de la cooperación económica entre mercaderes

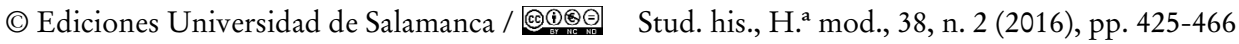


separados por la distancia geográfica o por condicionamientos de orden cultural ${ }^{1}$. El presente artículo pretende tener en cuenta esas recientes líneas de investigación a través del estudio de los conjuntos de cooperación interpersonal desarrollados por diversos hombres de negocios portugueses residentes en Madrid durante el reinado de Felipe IV (1621-1665), los cuales dirigieron sus intereses económicos tanto a las transacciones comerciales como a la contratación de asientos o rentas reales con la Real Hacienda de la Monarquía Hispánica.

El desarrollo de tales actividades exigió el recurso a corresponsales y agentes diseminados por distintos espacios geográficos de cara a la realización de operaciones como la compraventa y remisión de mercancías en el caso del comercio; la obtención de crédito de particulares, el pago de mesadas y el cobro de libranzas en la contratación de asientos; o la recaudación de derechos fiscales y la persecución de descaminos en los arrendamientos de rentas. Con el fin de lograr un correcto cumplimiento de tales comisiones, cabe plantearse las siguientes preguntas: ¿ En qué factores se fundaba la confianza depositada por esos hombres de negocios en agentes situados a distancias considerables? ¿De qué mecanismos disponían los mismos para controlar y/o penalizar las acciones de sus corresponsales y empleados? Ambas cuestiones están interrelacionadas puesto que si entendemos la confianza interpersonal como una expectativa en las acciones de otros individuos, esta ha de estar estrechamente ligada al marco institucional, social y cultural en que dichos individuos interactuaban.

Precisamente ello remite a los acalorados debates sostenidos desde la década de 1980 entre la Nueva Economía Institucional (New Institutional Economics) y la Nueva Sociología Económica (New Economic Sociology) en torno a los factores de la cooperación interpersonal y la utilidad del concepto de confianza como objeto de análisis. Ambas corrientes de pensamiento surgieron como respuesta a los postulados tradicionales de la Economía Clásica, para la cual las interacciones económicas se explicaban como resultado de transacciones entre individuos

1. Studnicki-Gizbert, D.: A Nation Upon the Ocean Sea. Portugal's Atlantic Diaspora and the Crisis of the Spanish Empire, 1492-1640. Nueva York, 2007; Trivellato, F.: The Familiarity of Strangers. The Sephardic Diaspora, Livorno and Cross-Cultural Trade in the Early Modern Period. New Haven-Londres, 2009; Lamikiz, X.: Trade and Trust in the Eighteenth-Century Atlantic World. Spanish Merchants and their Overseas Networks. Londres-Woodbridge, 2010; Aslanian, S.: From the Indian Ocean to the Mediterranean. The Global Trade Networks of Armenian Merchants from New Julfa. Berkeley-Los Ángeles, 2011; RiBEIRO, A. S.: Mechanism and Criteria of Cooperation in Trading Networks of the First Global Age. The Case Study of Simón Ruiz Network, 1557-1597. Tesis doctoral inédita, Universidad de Oporto, 2011; VANNESTE, T.: Global Trade and Commercial Networks: Eighteenth-Century Diamond Merchants. Londres, 2011.

(C) Ediciones Universidad de Salamanca / @®@@ Stud. his., H. ${ }^{a}$ mod., 38, n. 2 (2016), pp. 425-466 
racionales guiados por su interés particular en el marco de mercados anónimos. Una visión hasta cierto punto determinista que aislaba lo económico de las demás dimensiones de la realidad humana, como la social o la cultural. En respuesta a ello los distintos autores adscritos a la Nueva Economía Institucional trataron de encuadrar el desarrollo de actividades económicas como el comercio a larga distancia bajo los parámetros de la evolución institucional, entendiendo las instituciones como un sistema de factores sociales que conjuntamente generan una regularidad de comportamiento. Entre tales factores se cuentan la legislación, las creencias, las normas y las organizaciones ${ }^{2}$. De ese modo las instituciones serían conjuntos formales o informales desarrollados por la acción humana de cara a regular sus propias acciones.

Dentro de esta corriente cabe destacar el estudio de Avner Greif sobre los mercaderes judíos magrebíes durante los siglos XI y XII. Para Greif la colaboración económica entre dichos comerciantes se explicaba en función de la existencia de una «coalición» en cuanto que institución económica informal basada en un acuerdo implícito entre sus miembros para cooperar con otros individuos conformantes de la misma. Las fronteras de la coalición vendrían determinadas por el origen etno-religioso similar de sus conformantes, mientras que la eficacia de dicha coalición se sustentaría en un mecanismo de control de las reputaciones basado en el intercambio de información sobre las acciones y aptitudes individuales. A partir de ello los miembros de la coalición deberían decidir desde su racionalidad si los beneficios de un comportamiento honrado podían ser mayores a los del fraude, penalizado mediante sanciones informales en base a la reputación ${ }^{3}$. Las tesis de Greif muestran que no se estaría hablando de la articulación de relaciones de confianza. De hecho, a la hora de discutir acerca del propio concepto de

2. GreIF, A.: Institutions and the Path to the Modern Economy. Lessons from Medieval Trade. Nueva York, 2006, p. 30. Entre los autores más influyentes de la Nueva Economía Institucional se contó Douglass North, quien abordó la estrecha relación entre el desarrollo institucional y las prácticas económicas a lo largo de la historia. NoRTH, D. C.: Institutions, Institutional Change, and Economic Performance. Cambridge, 1990.

3. GreIF, A.: «Reputation and Coalitions in Medieval Trade: Evidence on the Maghribi Traders", The Journal of Economic History, vol. 49, 4, 1989, pp. 857-882. Posteriormente Greif comparó la coalición de mercaderes magrebíes con el marco institucional en el que operaron sus coetáneos genoveses, basado en un sistema de responsabilidad legal individual. GreIF, A.: Institutions and the Path..., pp. 58-90 y 269-304. Los presupuestos de Greif han sido duramente criticados por Jeremy Edwards y Sheilagh Ogilvie a raíz del escaso basamento empírico en que sustenta la existencia de la coalición de mercaderes magrebíes, así como la supuesta división cultural que evidenciarían las distintas formas de organización utilizadas por magrebíes y genoveses. Edwards, J., y OGILVIE, S.: «Contract enforcement, institutions, and social capital: the Maghribi traders reappraised», Economic History Review, vol. 65, 2, 2012, pp. 421-444.

(C) Ediciones Universidad de Salamanca / @@ Stud. his., H. ${ }^{a}$ mod., 38, n. 2 (2016), pp. 425-466 
confianza autores como Oliver Williamson y Timothy Guinnane han negado su vigencia real al señalar que lo que realmente subyace bajo ese término es el cálculo racional de los individuos en función del marco institucional en el que desarrollan sus interacciones económicas ${ }^{4}$. Desde ese punto de vista, ese cálculo de individuos racionales a la hora de asumir riesgos dependerá de la información y sanciones provistas por el contexto institucional. De ahí que Guinnane considere errónea la referencia a problemas de confianza o fiabilidad al estudiar las interacciones económicas en vez de centrarse en el análisis de los fallos institucionales.

Otros autores neoinstitucionalistas no se han mostrado tan críticos con el recurso al concepto de confianza, aunque se han aproximado al mismo como una variable más del «capital social» generado por un entorno institucional concreto ${ }^{5}$. Por ejemplo, a partir del estudio de las organizaciones gremiales durante el periodo moderno Sheilagh Ogilvie ha concebido la confianza como una propensión observable (y cuantificable) a depositar ciertas expectativas en individuos o instituciones. Ogilvie ha tratado de probar la existencia de distintos tipos de confianza en función de las características del capital social producido por determinadas instituciones, así como las repercusiones económicas que de ello se derivaban ${ }^{6}$. La Nueva Economía Institucional ha proporcionado así importantes avances teóricos y metodológicos de cara al análisis de los resortes de la cooperación económica. No obstante, ha tendido a atribuir un papel excesivo al contexto institucional y a la influencia del cálculo racional en los individuos, obviando el peso desempeñado por otros factores de carácter social o cultural en las interacciones económicas.

De ahí que esta tendencia haya sido tachada de funcionalista por la otra corriente surgida en respuesta a los excesos de la Economía Clásica: la Nueva Sociología Económica. Esta última supuso una vía alternativa de cara al análisis de los factores de la cooperación económica. Una de sus principales aportaciones fue la de la difusión por parte de Mark Granovetter de la noción de integración o arraigo (embeddedness) de las actividades económicas en la estructura social.

4. Williamson, O. E.: «Calculativeness, Trust, and Economic Organization», The Journal of Law E Economics, vol. 36, 1, 1993, pp. 453-486. Guinnane, T.: «Trust: A Concept Too Many», Jabrbuch für Wirtschaftsgeschichte / Economic History Yearbook, vol. 46, 1, 2005, pp. 77-92. Guinnane, T.: «Les économistes, le crédit et la confiance», Genèses, 79, 2010, pp. 6-25.

5. El capital social fue definido como el conglomerado de valor generado por un grupo de individuos al invertir recursos en el desarrollo de un conjunto de relaciones interpersonales (una red social). Coleman, J. S.: «Social Capital and the Creation of Human Capital», American Journal of Sociology, vol. 94, 1988, pp. S95-S120.

6. OgILvit, S.: «The Use and Abuse of Trust: Social Capital and its Deployment by Early Modern Guilds», Jabrbuch für Wirtschaftsgeschichte / Economic History Yearbook, vol. 46, 1, 2005, pp. 15-52.

(C) Ediciones Universidad de Salamanca / @®@@ Stud. his., H. ${ }^{a}$ mod., 38, n. 2 (2016), pp. 425-466 
Granovetter trataría de marcar distancia respecto a las tesis de autores neoinstitucionalistas como Oliver Williamson remarcando la influencia desempeñada por las relaciones interpersonales, y su estructuración en redes, en las interacciones económicas. Según Granovetter los individuos se hallan insertos en redes de carácter informal no orientadas en exclusiva a la consecución de objetivos económicos, sino también ligadas a otros elementos de carácter social o cultural ${ }^{7}$. A partir de estos presupuestos otros sociólogos como François Cusin han evaluado el peso de los mecanismos relacionales en la generación de confianza en empresas mercantiles, entendiendo la confianza como un sentimiento o creencia en las acciones de otros actores, y no tanto como una propensión cuantificable. Tratando de completar los presupuestos de Granovetter, Cusin incide en la necesidad de tener en cuenta no solo las propias interacciones interpersonales, sino también de otras realidades «estructurantes» como las políticas, las jurídicas, las normativas o las culturales ${ }^{8}$.

Por consiguiente, tanto la Nueva Economía Institucional como la Nueva Sociología Económica han ofrecido interesantes vías de análisis de la cooperación entre actores económicos. Ya sea incidiendo en el peso del contexto institucional o en de las estructuras socializantes a la hora de estudiar su reflejo en la forja de actitudes de confianza (o simplemente cálculo racional). En este trabajo se tratarán de combinar los presupuestos de ambas tendencias entendiendo la confianza como una expectativa de determinados actores en las acciones de otros. Dicha expectativa se verá incidida por diferentes factores jurídico-institucionales, pero sobre todo sociales y culturales.

\section{MARCO JURÍDICO-INSTITUCIONAL, REDES SOCIALES Y CORRESPONDENCIA}

Partiendo de tales premisas habrá que hacer una breve mención al entorno jurídico-institucional en el que operaron los hombres de negocios a estudiar en el presente artículo. Para ello se muestra de gran utilidad la consulta de un memorial redactado en 1625 por el licenciado García de Illán para el marqués de Montesclaros, gobernador del Consejo de Hacienda ${ }^{9}$. El memorial de este jurista judeoconverso

7. Granovetter, M.: «Economic Action and Social Structure: The Problem of Embeddedness», The American Journal of Sociology, vol. 91, 3, 1985, pp. 481-510.

8. Cusin, F.: «Relations marchandes et esprit d'enterprise: La construction sociale de la confiance», Revue Interventions économiques, 33, 2006, pp. 2-23.

9. El marqués de Montesclaros sería uno de los hombres de confianza del conde-duque de Olivares, valido de Felipe IV. Desde finales de 1622 se le había encomendado la presidencia de una recién creada Junta de Comercio, siendo nombrado gobernador del Consejo de Hacienda en julio de 1623. ElliotT, J. H.: El conde-duque de Olivares. El político en una época de decadencia. Barcelona, 2004, pp. 175-177.

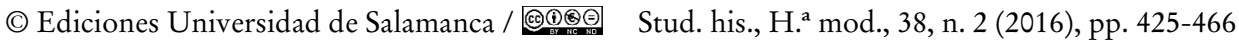


portugués, titulado Sobre las causas porque a benido en tanta quiebra el comercio en estos Reynos y las que le pueden bolber al ser que antes tenía, exponía en nombre de «los hombres de negocios y Mercaderes» residentes en Madrid la necesidad de remediar la quiebra del comercio en los dominios de Felipe $\mathrm{IV}^{10}$. Desde su punto de vista, la ruina del comercio estaba causada tanto por la poca estimación de la actividad mercantil como por la inseguridad económica derivada de las lagunas de la legislación castellana. Illán era un buen conocedor de la materia, pues desde su establecimiento en Madrid alrededor de 1619 se dedicaría a múltiples empresas mercantiles respecto a distintas localizaciones de la geografía europea y de las Indias de Castilla ${ }^{11}$.

El licenciado Illán se mostraba muy crítico con las deficiencias del entramado jurídico castellano a la hora de perseguir y castigar a los deudores y defraudadores, quienes podían recurrir a diversos artificios para evadir las obligaciones con respecto a sus acreedores. Como por ejemplo la ocultación o falsificación de sus libros de cuentas, situar sus deudas bajo el amparo de dote de sus esposas, acogerse a sagrado en las iglesias -o retirarse a las casas de los embajadores en caso de ser súbditos extranjeros-, retrasar mediante recursos legales los pleitos e, incluso, evadir la prisión haciendo gala de condición hidalga ${ }^{12}$. Para superar tales cortapisas Illán propuso la creación de un «Consulado y Universidad de Mercaderes» en Madrid, una institución formal dotada de jurisdicción particular para poder imponer sanciones a sus miembros ${ }^{13}$. Como bien es sabido, semejante proyecto no llegaría a ver la luz durante el reinado de Felipe IV, con lo cual los individuos ligados al ámbito del comercio siguieron experimentando las limitaciones del marco jurídico-institucional para poder penalizar los comportamientos deshonrosos. Una prueba de ello son los tediosos pleitos civiles, enormemente costosos

10. Archivo Histórico Nacional [en adelante AHN], Inquisición, leg. 3773, «Sobre las causas porque a benido en tanta quiebra el comercio en estos Reynos y las que le pueden bolber al ser que antes tenía. El licenciado García de Illán a 28 de julio de 1625 . Al marqués de Montesclaros».

11. Posteriormente Illán sería tesorero general de la renta de lanas entre 1627 y 1631, así como asentista de provisiones generales entre 1629 y 1634. En este último año se vería forzado a huir de la península Ibérica para evitar ser procesado por la Inquisición. Establecido posteriormente en Amberes, allí sería uno de los principales correspondientes de los asentistas de la Corona en Madrid. Boyajian, J. C.: Portuguese Bankers at the Court of Spain, 1626-1650. New Brunswick-New Jersey, 1983, pp. 35 y 152; Broens, N.: Monarquía y Capital Mercantil: Felipe IV y las Redes Comerciales Portuguesas (1627-1635). Madrid, 1989, pp. 62-64; EBbEn, M. A.: «Corona y comerciantes: García de Yllán, un mercader al servicio de Felipe IV», Diálogos Hispánicos, vol. 16, 1995, pp. 169-186.

12. AHN, Inquisición, leg. 3773, «Sobre las causas...», fol. 2r-v.

13. Idem, fol. $4 \mathrm{r}-7 \mathrm{v}$.

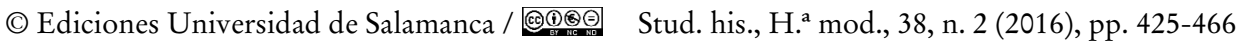


por los salarios de letrados, procuradores y escribanos, y que además podían prolongarse durante años sin que las partes afectadas consiguieran recuperar el dinero adeudado por corresponsales o agentes.

A pesar de lo cual cabe señalar que las acuciantes necesidades financieras de la Monarquía Hispánica desde finales del siglo xvi incidirían en el desarrollo de una serie de remuneraciones jurisdiccionales para sus asentistas -e incluso también para algunos arrendadores de rentas reales- plasmadas en el conocido como fuero de asentistas. Este incluía una serie de derechos exclusivos como la concesión de jurisdicción privativa para las causas civiles y criminales que pendieren durante la realización de un asiento, con inhibición de cualquier tribunal local o real salvo el Consejo de Hacienda. También incorporaba la exención del servicio militar, así como del pago de cualquier repartimiento fiscal de carácter extraordinario. Una de las principales plasmaciones del fuero de asentistas fue la de poder gozar de un juez conservador privativo para el periodo que transcurriese un determinado asiento o arrendamiento de rent $\mathrm{a}^{14}$. Sin embargo, estos privilegios jurisdiccionales estaban encaminados a garantizar que el hombre de negocios no sufriese inconvenientes en la ejecución de sus compromisos financieros con la Corona, tanto por parte de otros particulares como de diversas instituciones políticas o judiciales. Por consiguiente, no se mostraban tan efectivos de cara a supervisar, controlar o castigar los comportamientos deshonestos de los agentes y empleados de los asentistas y arrendadores de rentas.

Teniendo en cuenta lo referido es necesario plantearse la cuestión de si para los hombres de negocios, en este caso portugueses, sería posible depositar confianza en sus corresponsales y agentes únicamente en función de los frágiles mecanismos punitivos que semejante contexto jurídico-institucional ponía a su disposición. Según Illán tales limitaciones constituían una de las causas «porque ha venido a faltar el comercio en España en los naturales, y han retirado sus caudales los hombres de puntualidad, y ricos, que lo podían sustentar» ${ }^{15}$. Sin embargo, las deficiencias institucionales referidas por Illán en su arbitrio no vendrían a suponer un freno en la participación en diversas empresas comerciales y financieras de otros compatriotas portugueses residentes en territorio castellano entre las décadas de 1620 y 1650. Por esa misma razón creemos conveniente abordar la destacada influencia desempeñada en la articulación de la confianza interpersonal por una serie de comportamientos y prácticas insertos en los marcos de sociabilidad y cultura en

14. Sobre los privilegios jurisdiccionales concedidos por la Corona a sus asentistas en recompensa de sus «servicios económicos», Vid. SANZ Ayán, C.: Los banqueros y la crisis de la Monarquía Hispánica de 1640. Madrid, 2013, pp. 288-291.

15. AHN, Inquisición, leg. 3773, «Sobre las causas...», fol. 2v.

(C) Ediciones Universidad de Salamanca / @@ Stud. his., H. ${ }^{a}$ mod., 38, n. 2 (2016), pp. 425-466 
que estos actores interactuaban económicamente. De ese modo se enlazará con las tesis de la integración social de las actividades económicas propuesta por la Nueva Sociología Económica.

Dado que tales comportamientos juegan su papel dentro de la esfera de las interacciones sociales, para su reconstrucción se mostrará esencial el recurso a la metodología del análisis de redes sociales (Social Network Analysis) ${ }^{16}$. Desde una escala micro y de carácter inductivo, el análisis de redes sociales permite reconstruir y examinar las interacciones relacionales entre distintos actores sociales, así como evaluar sus características. Como ha señalado José María Imízcoz, este paradigma se muestra especialmente útil para la disciplina histórica de cara a insertar a los individuos en un contexto más global que supere el encorsetamiento de la secular segmentación de la realidad humana en distintas esferas -política, social, económica, cultural- o en esquemas categoriales clásicos -clase, nación, grupo religioso-. De ese modo, el análisis de redes sociales no solo posibilita el estudio de las relaciones interpersonales, sus características y sus contenidos reales, sino también de las interacciones de los individuos con el entorno social y cultural del que forman parte ${ }^{17}$.

En nuestro caso de estudio partiremos de la definición de «red» como un conjunto de interacciones interpersonales desarrolladas en un tiempo y espacio determinados. Ante la incapacidad de seleccionar para su análisis todas las relaciones personales que tuvieran lugar en un segmento concreto de la realidad social del pasado, se debe proceder al examen de extractos de la misma. Es por esa razón que se aplicará una perspectiva «egocentrada». Es decir, se analizarán los vínculos personales sostenidos por una serie de hombres de negocios portugueses que constituirán nuestro objeto de estudio (ego) con respecto a otros actores sociales (alteri) con los que interaccionaron durante un determinado periodo ${ }^{18}$. A su vez, se prescindirá del recurso a los modelos matemáticos y de representación visual desarrollados por el análisis de redes sociales, puesto que no se pretende examinar ni medir las características de los vínculos personales que componen esos conjuntos

16. Sobre la evolución de esta corriente y su aplicación en la disciplina histórica, LEMERCIER, C.: «Analyse de réseaux et histoire», Revue d'histoire moderne et contemporaine, 52/2, 2005, pp. 88-112; Antunes, C.: «A história da análise de redes e a análise de redes em história», História. Revista da FLUP Porto, IV Série, vol. 2, 2012, pp. 11-22.

17. Imízcoz Beunza, J. M.: «Actores, redes, procesos: reflexiones para una historia más global», História. Revista da FLUP Porto, III Série, vol. 5, 2004, pp. 115-140.

18. Una perspectiva que ya aplicaran historiadores como Zacarias Moutoukias. MoutouKIAS, Z.: «Negocios y redes sociales: modelo interpretativo a partir de un caso rioplatense (Siglo XVIII)», Caravelle, 67, 1997, pp. 37-55.

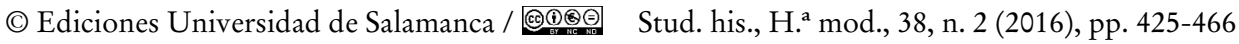


de relaciones ${ }^{19}$. Más bien, nuestro objetivo es abordar el contenido de esas interacciones y el peso desempeñado en ellas por una serie de prácticas socioculturales relacionadas con la articulación de la confianza en relaciones de cooperación económica. Por ello mismo el análisis ha de ser prioritariamente cualitativo. Así se tratará de evitar la tradicional división entre las concepciones «subsocializada» y «sobresocializada» que ha preponderado en el análisis de redes para centrarse en la agencia social y cultural llevada a cabo por los individuos conformantes de determinados conjuntos de interacciones personales ${ }^{20}$.

De cara al análisis cualitativo de los intercambios sociales sostenidos por un grupo de individuos resulta de crucial utilidad la correspondencia epistolar, una fuente documental que permite evaluar el contenido de relaciones desarrolladas en un marco temporal y geográfico concreto. Sobre todo con respecto a la anteriormente citada perspectiva egocentrada. Las cartas recibidas por un determinado individuo (ego) posibilitan la identificación de los actores con los que interaccionaba. Pero también de las funciones y atributos de esas relaciones, así como de los valores e ideas que, procedentes del entorno social y cultural, se transmitían en su seno. A pesar de su gran potencial para reconstruir redes egocentradas, la correspondencia epistolar no incluye aquellas relaciones, que por razones de proximidad o vecindad podían desarrollarse mediante encuentros cara a cara ${ }^{21}$. Para estas últimas es preciso recurrir a otras fuentes como la documentación notarial, los pleitos judiciales o, en el caso específico de algunos hombres de negocios de la nación portuguesa, los procesos de fe inquisitoriales ${ }^{22}$.

En el presente artículo se ha procedido a seleccionar y vaciar parcialmente el contenido de los epistolarios de cinco hombres de negocios cristãos-novos portugueses que desarrollaron sus actividades económicas desde el Madrid de las décadas centrales del XviI. Esas cartas custodiadas en la sección de Inquisición del Archivo

19. Respecto a algunas de las aplicaciones más recientes de dicha metodología en el terreno de la historia moderna, véanse los distintos trabajos recogidos en Crespo SolanA, A. (Ed.): Spatio-Temporal Narratives. Historical GIS and the Study of Global Trading Networks (15001800). Newcastle, 2014.

20. McLean, P. D.: The Art of the Network. Strategic Interaction and Patronage in Renaissance Florence. Durham-Londres, 2007, pp. 1-34.

21. Imízcoz Beunza, J. M., y Arroyo Ruiz, L.: «Redes sociales y correspondencia epistolar. Del análisis cualitativo de las relaciones personales a la reconstrucción de redes personales», REDES. Revista hispana para el análisis de redes sociales, vol. 21, 4, 2011, pp. 98-138.

22. Un ejemplo de fuentes alternativas puede verse en la reconstrucción del círculo de sociabilidad del artesano barcelonés Miquel Parets, llevada a cabo por James Amelang mediante la combinación del diario autobiográfico escrito por el propio Parets y diversa documentación notarial referente al mismo. Amelang, J. S.: The Flight of Icarus. Artisan Autobiography in Early Modern Europe. Stanford, 1998, pp. 80-114.

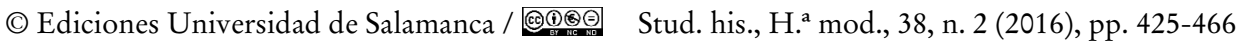


Histórico Nacional de Madrid proceden de los secuestros de bienes -y posteriores confiscaciones- realizados por distintos tribunales del Santo Oficio español contra dichos individuos portugueses a raíz de supuestos delitos de judaísmo ${ }^{23}$. Aunque el tamaño y estado de conservación de los referidos epistolarios varía según el caso, por lo general suelen ser lo bastante extensos para permitir la reconstrucción y análisis de redes egocentradas. Los individuos en cuestión a cuya correspondencia se ha recurrido son los que se citan a continuación.

Felipe Dias Guterres (c. 1598- ¿ ?), mercader natural de Aveiro del que se ha contado con las cartas recibidas entre 1630 y 1634, periodo durante el cual se dedicó a diversas transacciones comerciales con parientes, corresponsales y agentes diseminados por distintas localizaciones la Corona de Castilla, Portugal y Francia. Fue detenido por la Inquisición de Toledo en junio de 1636, de donde salió reconciliado en septiembre de ese mismo año ${ }^{24}$. Francisco Rodríguez Penamacor (c. 1595-1650), natural de la villa de Penamacor, del cual se ha analizado la correspondencia recibida entre los años 1641 y 1644, durante los cuales fue simultáneamente tesorero general de la renta del papel blanco y de estraza, así como de la renta del azúcar, conservas, cacao y chocolate ${ }^{25}$. En quiebra desde finales de 1648, tras su fallecimiento en agosto de 1650 buena parte de su correspondencia pasó a manos de otro de los hombres de negocios aquí estudiados: su sobrino Manuel Núñez Mercado (c. 1627-1656) ${ }^{26}$. También originario de Penamacor, para el caso de Mercado se han consultado las cartas conservadas para los meses de agosto y octubre de 1646, noviembre de 1647, diciembre de 1648 y enero de $1649^{27}$. Hasta 1647 Mercado fue agente y partícipe de los distintos asientos contratados para la provisión del Ejército de Extremadura por otro de sus tíos, Enrique Núñez ${ }^{28}$.

23. Estos epistolarios se hallan dispersos aleatoriamente en diferentes legajos, por lo general siguiendo como criterio el año o mes de las cartas recibidas.

24. AHN, Inquisición, leg. 142, exp. 2, Proceso de fe contra Felipe Díaz Gutiérrez (1636).

25. Adquirió la renta del azúcar, cacao y chocolate por un periodo de diez años contados a partir de enero de 1638 por un precio de 10.500 .000 maravedíes al año. AHN, Inquisición, leg. 5009, «Por Francisco Rodríguez Penamacor, Tesorero de la renta de los azúcares, \& conservas. Con el Fiscal, y con el Agente, y Procurador General del Reyno», s.f. A su vez arrendó la renta del papel por un periodo de seis años contados desde 1637 por una cuantía de 18.300.000 maravedíes anuales. Ibidem, Escritura de traslado de una libranza de Carlos Strata sobre la renta del papel, 16-4-1638.

26. La correspondencia de Penamacor conservada en los fondos del Archivo Histórico Nacional comprende dos periodos: 1641-1644 y 1646-1648.

27. El epistolario de Mercado incluye las cartas recibidas por él y por su hermano Juan Rodríguez Núñez (fallecido a mediados de 1649) entre los años 1643 y 1651.

28. Entre 1640 y 1647 Enrique Núñez proporcionaría mediante sus asientos un total de 1.334.000 escudos a la Real Hacienda. AHN, Inquisición, leg. 1896, exp. 1, Secuestro de bienes de Manuel Núñez Mercado (1652), fol. 101r-108r.

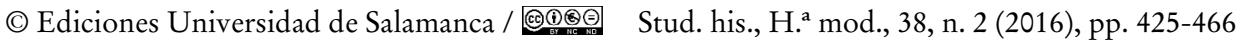


Tras el fallecimiento del último en septiembre de 1647 y la suspensión de pagos decretada por la Corona un mes después, Mercado lograría alcanzar en conjunción con sus hermanos Juan y Baltasar Rodríguez Núñez un acuerdo con el Consejo de Hacienda para salir de la lista de decretados. A cambio contratarían en marzo de 1648 un asiento de provisión de 200.000 escudos de vellón para los presidios de España ${ }^{29}$. A este negocio seguirían otros como el arrendamiento de la renta de la seda del Reino de Granada a finales de 1648 y la firma de un asiento de provisión de 240.000 escudos de vellón para el Ejército de Extremadura en febrero de $1649^{30}$. Mercado sería prendido por la Inquisición en abril de 1652, recayendo poco tiempo después en un estado de locura que conllevaría la suspensión de su causa y su posterior ingreso en el Hospital General de Valencia, donde fallecería el 7 de junio de $1656^{31}$.

Luis Fernández Pato (c. 1620- ¿ ?), natural de Vila Real, para el cual se han consultado primordialmente las cartas recibidas a lo largo de 1634 , cuando a pesar de su gran juventud comenzaría su andadura en solitario en el mundo de los negocios tras el establecimiento de su tío Pedro Fernández Pato en Amberes -y posteriormente Ámsterdam ${ }^{32}-$. Durante ese año, Pato centró sus intereses en la realización de diversas transacciones mercantiles entre Castilla, Portugal y Francia. Años después, Pato se convertiría en un destacado hombre de negocios, sobre todo tras casarse en segundas nupcias con Juana Díaz Capadocia en 1650. Esta era hija de Francisco López Capadocia (c. 1600-1666), el último de los hombres de negocios aquí tenidos en cuenta. Nacido en Vila Real, Capadocia fue asentista de provisión del presidio de Tánger entre 1641 y 1643 y del de Ceuta entre 1644 y

29. Archivo General de Simancas [en adelante AGS], Contadurías Generales [CCGG], leg. 142, Asiento tomado con Baltasar Rodríguez Núñez, Juan Rodríguez Núñez y Manuel Núñez Mercado sobre la provisión de 200.000 escudos de vellón para los Presidios de España, 5-3-1648. Entre 1634 y 1653 la gestión de las consignaciones necesarias para hacer frente a los distintos asientos para los Presidios de España corrió a cargo del genovés Octavio Centurión, marqués de Monesterio, bajo un contrato de factoría. SANZ Ayán, C.: Un banquero en el siglo de oro. Octavio Centurión, el financiero de los Austrias. Madrid, 2015, pp. 190-197.

30. Ibidem, Asiento tomado con Juan Rodríguez Núñez y Baltasar Rodríguez Núñez sobre el arrendamiento de la renta de la seda de la ciudad de Granada y su Reino, 31-12-1648. AGS, CCGG, leg. 143, Asiento tomado con Baltasar Rodríguez Núñez, Juan Rodríguez Núñez y Manuel Núñez Mercado sobre la provisión de 240.000 escudos de vellón para el Ejército de Badajoz, 18-2-1649.

31. Archivo Diocesano de Cuenca [en adelante ADC], Inquisición, leg. 486, exp. 6531, Proceso de fe contra Manuel Núñez Mercado (1652), fol. 135r-137v, y 148r-154v.

32. Su correspondencia cubre diversos años entre 1634 y 1663. Respecto a la participación de Pato y otros de sus parientes en Francia y en las Provincias Unidas en diversas actividades de contrabando, Vid. López Belinchón, B. J.: “"Sacar la sustancia al Reino”. Comercio, contrabando y conversos portugueses, 1621-1640», Hispania. Revista Española de Historia, LXI/3, 209, 2001, pp. 1017-1050.

(C) Ediciones Universidad de Salamanca / @®@@ Stud. his., H. ${ }^{a}$ mod., 38, n. 2 (2016), pp. 425-466 
$1646^{33}$. Precisamente se han seleccionado las cartas recibidas entre enero y agosto de 1644, periodo durante el cual culminó la negociación para la contratación del asiento de Ceuta y dio inicio a la provisión de la plaza norteafricana. En 1650 Capadocia arrendaría junto a su yerno Pato la renta de las salinas de Andalucía tierra adentro, que conservarían hasta 1653, cuando ambos fueron apresados por los tribunales inquisitoriales de Valladolid y Sevilla respectivamente. Tras ser liberados entre 1655 y 1656, tomaron en 1658 la renta de las alcabalas y tres por ciento de Córdoba que Capadocia y Pato gestionaron hasta que de nuevo fueran detenidos por la Inquisición en abril de 1663. Capadocia fallecería en las cárceles secretas de Toledo en febrero de 1666 tras ser sometido a tormento unos meses antes $^{34}$. Mientras tanto, Pato salió reconciliado por el Santo Oficio de Cuenca en 1670 , año en el que perdemos su rastro vital ${ }^{35}$.

Estos cinco hombres de negocios hasta aquí citados son en mayor o menor medida representativos de una parte de la élite socioprofesional judeoconversa portuguesa que jugó un rol destacado en las finanzas de la Monarquía Hispánica durante el reinado de Felipe IV $^{36}$. A partir del enfoque egocéntrico obtenido mediante la consulta de sus respectivos epistolarios se prestará atención en primer lugar al rol desempeñado por la transmisión de información mediante las cartas, no solo en la implementación de determinadas actividades económicas, sino especialmente en la forja de los valores de una buena correspondencia. De modo que mediante la observación del estilo y contenido de las cartas accederemos al papel de la cultura en la correspondencia de negocios. En segundo término, se analizará la importancia de la reputación en cuanto que valoración subjetiva en el día a día de todo actor económico. También se observará el estrecho vínculo de las interacciones sociales epistolares con la gestación, valoración y conservación de las

33. Para el asiento de Tánger, AGS, CCGG, leg. 135-2, Asiento tomado con Francisco López Capadocia sobre la provisión de la plaza y presidio de Tánger, 7-9-1641. Respecto al de Ceuta, Archivo Histórico de Protocolos de Madrid [en adelante AHPM], protocolo 5411, Francisco de Yanguas, 9-5-1644, fol. 81r-86v.

34. Las dos causas inquisitoriales contra Capadocia pueden consultarse en: AHN, Inquisición, leg. 161, exp. 5, Proceso de fe contra Francisco López Capadocia (1653-1655). Idem, exp. 9, Proceso de fe contra Francisco López Capadocia (1663-1670).

35. ADC, Inquisición, leg. 524, exp. 6749, Proceso de fe contra Luis Fernández Pato (16631670).

36. Sobre su caracterización como conformantes del estrato superior del grupo socioprofesional del comercio y las finanzas, sus procesos de movilidad social y sus relaciones con las élites políticas de la Monarquía Hispánica, Vid. Sánchez Durán, A.: «Los hombres de negocios portugueses: una élite profesional en la Castilla del siglo xvir. Posibilidades de movilidad social e intermediación», Tiempos Modernos. Revista electrónica de Historia Moderna, vol. 8, 31, 2015, pp. 193-220.

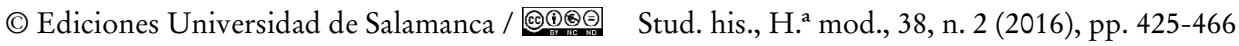


reputaciones individuales, y su peso en la creación o conservación de la confianza interpersonal. Por último, se comprobará la influencia de las consideraciones en torno a la reputación como criterio de selección y reclutamiento de agentes.

\section{INFORMACIÓN Y CULTURA EN LAS INERACCIONES EPISTOLARES}

La correspondencia epistolar constituyó sin duda uno de los pilares de las actividades económicas a media y larga distancia durante los siglos modernos. Más aún si cabe con anterioridad al surgimiento de periódicos y otro tipo de fuentes impresas de difusión pública, cuya aparición tendría lugar a partir de finales del siglo Xvir. De ahí que resulte una fuente de gran riqueza y variedad informativa sobre las variables que incidían en el comercio y las finanzas: precios de mercancías, premios de seguros, tipos de cambio o de interés, cuentas de negocios, disponibilidad de medios de transporte, etc. Del mismo modo, esta tipología documental proporciona referencias sobre las coyunturas políticas, militares e incluso climáticas que podían llegar a condicionarlas ${ }^{37}$. La transmisión de información mediante cartas permitía afrontar los riesgos inherentes al desempeño de negocios más allá del ámbito local de residencia, limitando la incertidumbre sobre contextos que solo podían ser conocidos mediante la intercesión de terceros. Las cartas remitidas por los corresponsales que conformaban las redes egocentradas de los individuos portugueses anteriormente referidos son un buen ejemplo de ello.

Es el caso de Francisco Gómez Téllez, quien tras establecerse en Sevilla a mediados del año 1630 proporcionó todo tipo de información respecto a los mercados local e indiano como agente comisionado de Felipe Dias Guterres y sus socios de Burdeos. Así, en carta de 6 de agosto de 1630 detalló todas las mercancías llegadas a Sevilla con la flota de Nueva España, notificando además que la escasez de seda fina para tejidos proporcionaría buenas oportunidades de negocio con dicho género:

advirto que seda fina para tesidos será bonisima fazenda porque a frota não traz huma libra, nem averá athé o ano que vem frota de Nova Espanha que a possa trazer, e asi podendo VM aver alguma o terei por bom emprego para esta çidade como o tempo mostrará38.

37. Ribeiro, A. S.: «Letras de câmbio e correspondência comercial como materiais da história. O acto de cooperar sob olhares distintos», CEM Cultura, Espaço E Memória: Revista do CITCEM, 2, 2011, pp. 159-169.

38. AHN, Inquisición, leg. 246, caja 2, carta de Francisco Gómez Téllez (Sevilla) a Felipe Dias Guterres (Madrid), 6-8-1630.

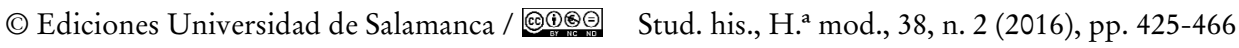


Meses después aconsejaba a Felipe Dias la pertinencia de la remisión de tejidos ruanes para la provisión de la siguiente flota con destino a Nueva España, considerando que serían tenidos casi por «ouro» y recordando la importancia crucial de esos textiles en el abastecimiento de la flota novohispana: «será ymposível aprestarse frota sem que venhão navios daly com fazendas que são o nervio da frota» ${ }^{39}$.

No cabe duda de que la posesión de información sobre las condiciones de determinados mercados permitía anticiparse a posibles contingencias y conseguir el mayor margen de beneficio en cualquier tipo de transacción comercial. Por ejemplo, a finales de 1633 Manuel de Oliveira Geta informaba a Pedro Fernández Pato de las grandes posibilidades que tendría su sobrino Luis Fernández Pato de «faser bem negosio» si adquiriese hierro en Bilbao para vender posteriormente en el puerto portugués de Aveiro: «que hé fasenda que tem boa saída nesta villa he pode ser que gostara do negósio he que tirara deste negósio desta vila muito dinheiro ${ }^{40}$. Parece que el consejo de Oliveira Geta surtió efecto, pues en febrero de 1634 Luis recibía una carta de Alejandro de Aguilar - un encomendero vasco de Guernica- en respuesta a una petición anterior de información sobre los precios del hierro de cuatro puntas y sobre la disponibilidad de navíos desde Bilbao a Aveiro. Aguilar recomendaba en dicha carta optar por el hierro de banda, o bijuela, por costar 4 o 5 reales menos por quintal y «por haver faltado estos días portugueses que lo compran» ${ }^{41}$.

Estos ejemplos muestran cómo la información se convertía así en la espina dorsal de los intercambios económicos a media o larga distancia. Así lo corrobora Jeremy Baskes en el caso del comercio transatlántico a fines del siglo xviII, pues los mercaderes españoles involucrados en el mismo eran reacios a participar en empresas sobre las que poseyeran escasa o poco fiable información. Ello explica la necesidad de contar con corresponsales y agentes situados en distintos centros de interés que posibilitasen un flujo constante de noticias sobre las condiciones económicas, políticas y climáticas ${ }^{42}$. Pero esa circulación de información no solo incidía en la generación de certidumbre y en la minimización de riesgos en el ámbito del comercio, sino también en el de la gestión de asientos y rentas reales.

39. Ibidem, carta de Francisco Gómez Téllez (Sevilla) a Felipe Dias Guterres (Madrid), 15-10-1630.

40. AHN, Inquisición, leg. 3793, carta de Manuel de Oliveira Geta (Aveiro) a Pedro Fernández Pato (Madrid), 15-12-1633.

41. Ibidem, carta de Alejandro de Aguilar (Guernica) a Luis Fernández Pato (Madrid), 13-2-1634.

42. Baskes, J.: «Communication Breakdown: Information and Risk in Spanish Atlantic World Trade during an Era of "Free Trade" and War», Colonial Latin American Review, vol. 20, 1, 2011, pp. 35-60.

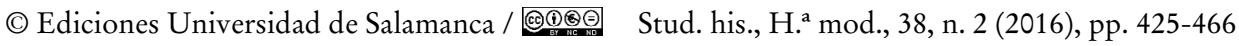


Por ello mismo, en agosto de 1646 Diego de Salvatierra y del Burgo, regidor de Salamanca y factor en dicha ciudad de Enrique Núñez y su sobrino Manuel Núñez Mercado, avisaba al último de la inconveniencia de recibir como parte de las consignaciones del asiento que estaba negociando con la Corona una libranza superior a 12 millones de maravedíes en la tesorería de millones salmantina, dada la miseria reinante en la localidad y su partido ${ }^{43}$. Para cualquier asentista resultaba fundamental que las consignaciones, es decir, las rentas y efectos con los que se compensaban tanto el principal como los intereses de la cantidad prestada, fuesen saldadas con la máxima prontitud posible tras realizar los anticipos ${ }^{44}$. De ahí que fuera de vital importancia contar con la mayor información posible del estado en que se encontraba cada renta para alcanzar las mejores condiciones de cobro en las negociaciones con los ministros del Consejo de Hacienda.

Además de posibilitar la transmisión de la información necesaria para encarar con éxito sus negocios, las interacciones epistolares permitían a estos hombres de negocios portugueses recabar las opiniones y consejos de sus corresponsales y agentes. Provenientes estas tanto de su propia experiencia profesional como de su mayor conocimiento de las condiciones de los mercados en los que desempeñaban sus labores. Mediante el examen de las cartas se puede corroborar que decisiones tan trascendentales como el arrendamiento de una renta real podían llegar a ser consultadas con corresponsales incluso ajenos al círculo familiar, tenido a priori como el de más confianza. Es lo que ocurrió en el caso de Luis Fernández Pato, al parecer interesado en tomar la renta de las lanas a principios de 1640. Con motivo de tal pretensión su corresponsal Diego López Torres -por entonces tesorero general de la renta de las salinas de Andalucía tierra adentro- le aconsejaría no involucrarse en dicho negocio debido al descenso del premio de la plata tras el consumo del vellón decretado a finales de $1638^{45}$ :

En quanto a la renta de las lanas bien save VM que la primera caussa de cargar muchas los años passados a ssido el mucho premio que a balido la plata [...]. Oy con este consumo de vellón berá VM benir la plata a tan bajo preçio que bendría a haver poca diferencia de una moneda a otra [...], ya que VM se quiere meter en

43. AHN, Inquisición, leg. 3923, carta de Diego de Salvatierra y del Burgo (Salamanca) a Manuel Núñez Mercado (Madrid), 25-8-1646.

44. SAnZ Ayán, C.: Los banqueros y la crisis..., pp. 60-68.

45. Sobre el consumo de vellón de 1638 y sus consecuencias, García Guerra, E. M.: «La moneda de vellón: un instrumento al servicio de la fiscalidad del Estado Moderno: las Cortes», Cuadernos de Historia Moderna, vol. 21, 1998, pp. 59-101. Respecto al negocio de la exportación de lanas castellanas en los años precedentes, IsRaEL, J. I.: «Spanish Wool Exports and the European Economy, 1610-40», The Economic History Review, New Series, vol. 33, 2, 1980, pp. 193-211.

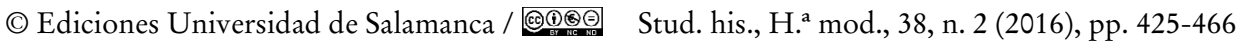


negoçio yo quisiera fuera en alguno menos trillado que este por donde le pido por amor de Dios bea cómo se mete en él. Y ay una dificultad grandísima oy en estas rentas que como su Magestad toma las medias anatas cada año éstas hazen rebentar un hombre ${ }^{46}$.

A pesar de todo lo referido, las interacciones epistolares por sí solas no permitían solventar el principal problema al que debían enfrentarse estos negociantes portugueses: el de cómo confiar en corresponsales, factores o agentes a los que no se podía monitorizar personalmente. Dada la asimetría informativa existente entre un actor económico establecido en un mercado del que era conocedor y otro cualquiera que le encomendara una determinada comisión desde una localización distante, el primero podría verse tentado a estafar al último. Esa era la potencial fuente de desconfianza que historiadores y economistas denominan como el problema de la agencia (the agency problem $)^{47}$. En apartados posteriores trataremos de analizar cómo las valoraciones sobre la reputación podían contribuir a solventar esa falla en la confianza interpersonal.

Por el momento nos gustaría reseñar el papel desempeñado por las cartas en la transmisión de una serie de códigos o valores culturales que pretendían cimentar la confianza respecto a los receptores de las mismas. Ante la imposibilidad del contacto físico entre corresponsales separados por la distancia, las cartas se convertían en el único vehículo por el que podían garantizar su honestidad a través de lo que podríamos denominar como valores de una buena correspondencia. Sebouh Aslanian y Francesca Trivellato comprobaron que las cartas escritas tanto por los mercaderes armenios de Nueva Julfa como por sus homólogos judíos sefardíes de Livorno compartían una serie de estructuras formales y elementos estilísticos. Es lo dieron en llamar la «etiqueta» o el «arte» de las cartas mercantiles ${ }^{48}$. Lo mismo se puede detectar en las epístolas recibidas por los hombres de negocios portugueses aquí estudiados, ya fueran remitidas por parientes, por otros compatriotas portugueses o por corresponsales de distinta adscripción nacional. Esa uniformidad de estilo en cartas remitidas por individuos de diversos orígenes o contextos es lo que lleva a Trivellato a defender la formación de una comunidad mercantil global desde los siglos XVII y XviII, cuyos valores se habrían transmitido precisamente por medio de las interacciones sociales epistolares. De hecho, la escritura de cartas se

46. AHN, Inquisición, leg. 3830, carta de Diego López Torres (Sevilla) a Luis Fernández Pato (Madrid), 27-3-1640. 9.

47. Baskes, J.: «Communication Breakdown...», p. 44. Lamikiz, X.: Trade and Trust..., p.

48. Aslanian, S.: From the Indian Ocean..., pp. 86-120. Trivellato, F.: The Familiarity of Strangers..., pp. 177-189.

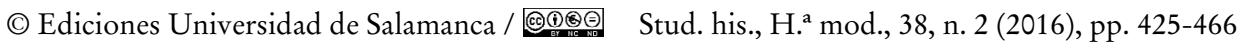


convirtió en una práctica social y discursiva mediante la cual los correspondientes recurrían a estrategias de cortesía de cara a conseguir determinados objetivos ${ }^{49}$. La etiqueta común empleada en la correspondencia no solo vendría dada por la experiencia cotidiana en la escritura epistolar, sino que los manuales y formularios de cartas que proliferaron en la Europa moderna desempeñarían también una notable influencia ${ }^{50}$.

Sin duda, el lenguaje empleado en las cartas ejercía un rol importantísimo en la generación de confianza entre distintos agentes económicos. El recurso a la cortesía iba acompañado por lo general de alusiones en las que el remitente mostraba interés respecto a la salud del destinatario de la carta, deseándole la conservación de la misma y ofreciéndose a su entero servicio. Así se puede observar en un fragmento de carta seleccionado al azar: «Reciví su carta de VMd que la estimé por tener buenas nuevas de su salud en primer lugar que nuestro señor le aumente como este amigo le desea, la mía es buena para servir a $\mathrm{VMd} »^{51}$. Con ligeras diferencias, los encabezados de las cartas solían respetar esta fórmula que sin duda pretendía combinar respeto, implicación y entrega hacia el receptor de la misiva. Las muestras de servilismo y subordinación eran muy comunes sobre todo cuando el remisor de la carta se hallaba al servicio del destinatario como su factor o agente comisionado. Es el caso de la misiva enviada en diciembre de 1648 por Rafael de Amezquita al asentista Juan Rodríguez Núñez justo después de haber sido nombrado visitador en la renta de la seda de Granada por su hermano Baltasar Rodríguez Núñez:

El correo passado di a VMd quenta cómo llegué a esta ciudad [...] y aver vessa[do] la mano al señor Balthasar Rodríguez de quien e recibido particular merced y honrra que protesto reconoçer siempre para servir a VMds en todo quanto me mandare [...]. Dicho señor me ocupa en visitar el partido a que acudiré con todo cuydado haçiendo todo mi dever ${ }^{52}$.

Un ejemplo similar lo encontramos en una carta escrita en 1630 por Simón de Fonseca Piña a Felipe Dias Gutierres, para quien entonces actuaba como agente

49. Del Lungo Camiciotti, G.: «Letters and Letter Writing in Early Modern Culture: An Introduction", Journal of Early Modern Studies, 3, 2014, pp. 17-35.

50. Así lo comprueba Vanessa de Cruz a través de las mujeres del ámbito de la Corte española durante los siglos XVi y XVII. De Cruz Medina, M. V.: Cartas, Mujeres y Corte en el Siglo de Oro. Tesis doctoral inédita, Universidad Complutense de Madrid, 2010, pp. 42-79.

51. AHN, Inquisición, leg. 3887, caja 2, carta de Francisco Rodríguez Villarreal (Málaga) a Francisco López Capadocia (Madrid), 19-4-1644.

52. AHN, Inquisición, leg. 3945, carta de Rafael de Amezquita (Granada) a Juan Rodríguez Núñez (Madrid), 29-12-1648.

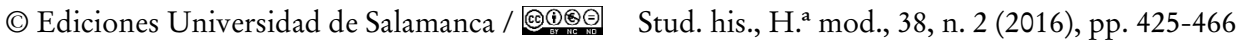


comisionado en Sevilla: «cem tudo folgarei açertar a servilo que sempre fui e serei toda a vida seu amigo leal, e servidor como o tempo lhe mostrará, e confio em Deus tenha bom avansso a vida por minha mão ${ }^{53}$. Tanto Rafael de Amezquita como Simón de Fonseca Piña declaraban así a sus respectivos correspondientes su voluntad de cumplir correctamente con sus cometidos.

El recurso a esas expresiones de consagración al servicio del prójimo era también recurrente entre corresponsales mercantiles. Así, en noviembre de 1640 Antonio de Lorensi -un destacado mercader bilbaíno- finalizaba de la siguiente manera una carta en respuesta al interés de Luis Fernández Pato en conocer la disponibilidad de navíos para transportar lanas hasta Hamburgo o un puerto inglés: «se podrá VM servir del aviso y a mí mandarme en que le sirba que lo aré de buena gana $»^{54}$. Incluso sucedía lo propio con individuos de estatus social superior al de los destinatarios de las epístolas. En junio de 1644 don Juan Fernández de Córdoba y Coalla, marqués de Miranda de Auta y gobernador de Ceuta hasta fechas recientes, se dirigía a Francisco López Capadocia, nuevo asentista del presidio norteafricano, en los términos siguientes: «Los pocos días que estubiere en esta plaça y en qualquiera parte que me hallare me tendrá VMd para serbirle con muy buena voluntad $»^{55}$.

No obstante, la etiqueta del lenguaje no bastaba por sí misma para sentar los cimientos de la confianza. Para ello era preciso recurrir también a la práctica de una buena correspondencia, basada fundamentalmente en el respeto de la reciprocidad en el intercambio de cartas. Todo actor económico esperaba que sus corresponsales respondieran con la mayor brevedad y claridad posible sus cartas. De ahí que las quejas fueran comunes cuando se producían retrasos en la remisión de las misivas o el contenido de las mismas adolecía de vaguedad. Errores poco deseables dada la importancia crucial de la información para el buen suceso de los negocios. Esa es la razón de que los corresponsales debiesen ofrecer argumentos convincentes cuando sus respuestas no llegaban a tiempo o eran imprecisas. Así

53. AHN, Inquisición, leg. 246, caja 2, carta de Simón de Fonseca Piña (Sevilla) a Felipe Dias Guterres (Madrid), 12-11-1630. Años después Simón de Fonseca Piña casaría con una hija del acaudalado Gaspar Rodríguez Pasariño, disfrutando de una exitosa trayectoria en el mundo de los negocios como arrendador de rentas reales y asentista hasta su muerte a principios del reinado de Carlos II. SAnz Ayán, C.: Los banqueros de Carlos II. Valladolid, 1988, pp. 342-344. Sobre los hermanos Pasariño (o Passarinho) de Sevilla, Boyajian, J. C.: Portuguese Bankers..., pp. 53-54.

54. AHN, Inquisición, leg. 3830, carta de Antonio de Lorensi (Bilbao) a Luis Fernández Pato (Madrid), 23-11-1640.

55. AHN, Inquisición, leg. 3887, caja 1, carta del Marqués de Miranda (Ceuta) a Francisco López Capadocia (Madrid), 24-6-1644.

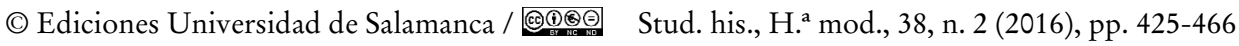


le sucedería a Francisco de Beroiz Fagola, encomendero vizcaíno al servicio de Manuel Núñez Mercado en San Sebastián, tras ser interpelado en octubre de 1646 sobre esa misma cuestión:

díceme VM que me ha escrito algunas cartas y que de ninguna ha tenido respuesta, a que respondo que no la puede tener VM sin tiempo, pero para aora havrá recebido cartas mías en respuesta de las de VM porque a ninguna he dexado de responder ${ }^{56}$.

Del mismo modo se entienden las quejas de Simón Rodríguez Núñez, pariente y factor de Manuel Núñez Mercado en el negocio de los asientos, tras la suspensión de consignaciones decretada por la Corona en octubre de $1647^{57}$. Acosado por sus acreedores en Sevilla, un desesperado Simón Rodríguez Núñez exhortaba a Manuel a ser más franco respecto a sus negociaciones con los miembros del Consejo de Hacienda y de la Junta del Decreto:

VM [...] me escrive de manera que no entiendo en el estado que allá están las cosas ni los que an leydo su carta saven declarármela porque no lo entienden. Lo que le pido es que me escriva con claridad de todo lo que ubiere bueno u malo pues será razón ya que oy no tenemos otro consuelo más que saber de allá con certeza en lo que esto a de parar ${ }^{58}$.

Por todo ello podemos afirmar que el correcto respeto de la reciprocidad en el intercambio de cartas, así como la claridad del contenido de las mismas garantizaban esas prácticas de buena correspondencia. Lo anterior, unido a la propia etiqueta del lenguaje, exterioriza el papel desempeñado por la cultura en la forja de la confianza. Una cultura cuyos valores y prácticas se transmitían a través de las interacciones epistolares entre individuos separados entre sí por el espacio geográfico.

\section{El ROL DE LA REPUTACión y SU VALORACión a TRAVÉS DE LAS CARTAS}

Durante los siglos modernos la reputación vino a desempeñar un papel crucial en la construcción de la confianza entre agentes económicos en cuanto que valoración colectiva de la integridad y prestigio de un individuo en un determinado círculo social. Por esa misma razón la reputación ha sido considerada como uno

56. AHN, Inquisición, leg. 3923, carta de Francisco de Beroiz Fagola (San Sebastián) a Manuel Núñez Mercado (Madrid), 13-10-1646.

57. Para lo referente a la bancarrota de 1647 y sus repercusiones, SANZ Ayán, C.: Los banqueros y la crisis..., pp. 177-207.

58. AHN, Inquisición, leg. 3945, carta de Simón Rodríguez Núñez (Sevilla) a Manuel Núñez Mercado (Madrid), 5-11-1647.

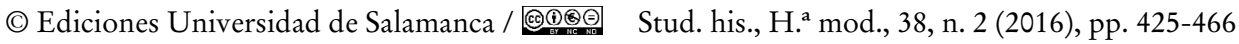


de los fundamentos de las actividades comerciales a larga distancia, al posibilitar la disminución de los riesgos mediante la selección de corresponsales fiables. La posesión de una buena reputación llegaría a convertirse en el bien más preciado de todo mercader al establecer su posición dentro de una comunidad comercial y permitirle asentar correspondencias con actores económicos situados en mercados distantes. Incluso también para preservar perspectivas de futura empleabilidad si se trataba del caso de factores o agentes comisionados. Y dado que las reputaciones dependían tanto del comportamiento previo como del juicio colectivo, se podría afirmar que estaban en continua variación ${ }^{59}$.

Ese importante rol de las reputaciones no era exclusivo del ámbito de las relaciones comerciales. Como se demostrará a lo largo de este apartado las apreciaciones en torno a la reputación ejercían una influencia crucial en otras actividades económicas que también requerían contar con la participación de agentes de confianza, como el arrendamiento de rentas reales o la gestión de asientos ${ }^{60}$. De hecho, como prueban las trayectorias vitales de buena parte de los hombres de negocios portugueses establecidos en Castilla durante el siglo XvII, esas ocupaciones fiscales y financieras estuvieron estrechamente ligadas con el comercio ${ }^{61}$. El análisis de la correspondencia permite valorar en su justa medida el lugar que las cartas ocupaban a la hora de juzgar las reputaciones individuales. La combinación de la información transmitida mediante las cartas con la etiqueta empleada en las mismas sería clave en la construcción, evaluación y destrucción de las reputaciones.

59. Lamikiz, X.: «Un “cuento ruidoso": Confidencialidad, reputación y confianza en el comercio del siglo XVIII», Obradoiro de Historia Moderna, 16, 2007, pp. 113-142. STUDNICKIGizBerT, D.: A Nation Upon the Ocean..., pp. 84-88. Sobre la estrecha relación de la reputación con la forja de la confianza necesaria para encarar los riesgos asociados al crédito interpersonal, Muldrew, C.: The Economy of Obligation. The Culture of Credit and Social Relations in Early Modern England. Londres, 1998, pp. 148-172. Mathias, P.: «Risk, Credit and Kinship in Early Modern Enterprise», en McCusker, J. J., y Morgan, K. (Eds.): The Early Modern Economy. Cambridge, 2000, pp. 15-35. VANNESTE, T.: Global Trade and Commercial Networks..., pp. 91-95.

60. Para algunos hombres de negocios portugueses la conservación de una buena reputación y su combinación con estrategias socioculturales destinadas a la construcción de una imagen ideal en los ambientes cortesanos resultaría crucial en la culminación de exitosos procesos de movilidad ascendente. Es el caso de la familia Cortizos, cuyos miembros llegarían a acceder a la nobleza titulada de Castilla a pesar de su origen judeoconverso. SANZ AyÁn, C.: «Procedimientos culturales y transculturales de integración en un clan financiero internacional: los Cortizos (siglos XVII y XVIII)», en Yun Casalilla, B. (Dir.): Las redes del imperio. Élites sociales en la articulación de la Monarquía Hispánica, 1492-1714. Madrid, 2009, pp. 65-94.

61. El caso de Fernando Montesinos resulta muy ilustrativo al respecto. López BeLinCHón, B. J.: Honra, libertad y hacienda. Hombres de negocios y judios sefardies. Alcalá de Henares, 2001.

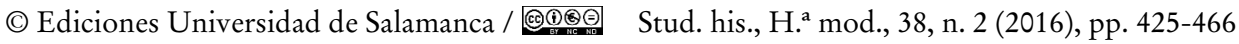


Por ello puede señalarse que la reputación de agentes establecidos a considerables distancias era forjada principalmente a través de los intercambios epistolares ${ }^{62}$.

Así puede observarse en lo acontecido en la administración sevillana de las rentas del papel y del azúcar y conservas arrendadas por Francisco Rodríguez Penamacor. Tras el fallecimiento de su cuñado Juan Rodríguez Ferreirín en diciembre de 1641, hasta entonces su administrador en Sevilla, Penamacor se decantaría provisionalmente por Francisco Rodríguez Lameira para asumir la dirección de dicha administración. A la vez reservaría grandes responsabilidades en la misma a su propio sobrino Antonio López Ferreirín, un mozo de apenas 20 años de edad. En concreto en relación al cobro de los derechos de la renta del azúcar, una apuesta arriesgada de Penamacor teniendo en cuenta que la mayor parte de los ingresos de dicha renta se obtenían a través de Sevilla y los restantes puertos ligados al tráfico indiano, como Sanlúcar de Barrameda o Cádiz. Por esa razón no es de extrañar que en enero de 1642 Ferreirín recurriese a la correspondencia para asegurar a su tío Francisco el buen porvenir que habría de tener la renta por su mano: «yo tengo más ocasión para tener el mejor negoçio desta ciudad, VMd por vida suya mire esto con buenos ojos» ${ }^{63}$.

Sin embargo, pocos meses después el crédito del joven Ferreirín ante su tío comenzaría a resentirse como consecuencia de las críticas expresadas por Lameira en sus cartas a Penamacor. En abril de 1642 Lameira se quejaba de que Ferreirín hubiese gastado 3.500 reales en el alquiler y salarios de la tripulación de un pequeño barco para navegar hasta Sanlúcar y poner cobro a los azúcares llegados con los galeones de Tierra Firme, asegurando que habría bastado con la mitad de dicha cantidad ${ }^{64}$. Viendo su reputación cuestionada, Ferreirín trataría de defender su propia honradez a la vez que censuraba las denuncias realizadas por Lameira a sus espaldas:

Yo le [he] dicho mi parezer al señor Lamera que los honbres no an de tratar más sino de lo que toca al negoçio y no más. Y no meterse con chismes [...] que en esto pareze a honbre de la Puerta del Sol [...]. Yo sé mui bien lo que me conbiene y sé guardar el dinero tan bien como otro y gastarlo a su tiempo sin desbanecimientos ni locuras, en fin yo soy enemigo de alavarme sino el pan pan y el bino bino. Siempre por el camino de la verdad y nunca a de hallar VMd otra $\cos a^{65}$.

62. Trivellato, F.: The Familiarity of Strangers..., pp. 167-176.

63. AHN, Inquisición, leg. 3839, caja 1, carta de Antonio López Ferreirín (Sevilla) a Francisco Rodríguez Penamacor (Madrid), 28-1-1642.

64. AHN, Inquisición, leg. 4396, carta de Francisco Rodríguez Lameira (Sevilla) a Francisco Rodríguez Penamacor (Madrid), 15-4-1642.

65. AHN, Inquisición, leg. 3839, caja 1, carta de Antonio López Ferreirín (Sevilla) a Francisco Rodríguez Penamacor (Madrid), 15-4-1642.

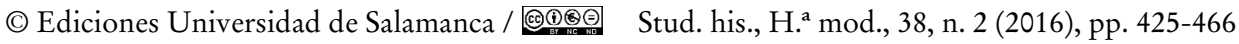


A partir del mes de julio la rivalidad entre Ferreirín y Lameira llegó a su punto álgido después de que Penamacor confiase definitivamente la administración sevillana de las rentas al primero. Por el testimonio de Ferreirín sabemos que Lameira, además de negarse a entregarle las cuentas de la renta del papel, le acusaba de haber ido a Madrid «a quitarle esta administración con cautela [...] por no estar debaxo de su dominio» con la supuesta finalidad de gastar el dinero de las rentas «sin quenta ni razón». Un conjunto de calumnias que Antonio denunciaba en carta a su tío Francisco Rodríguez Penamacor porque «llegan a la reputación». A lo cual añadía que el objetivo de Lameira no sería otro sino el siguiente: «él trata de descomponerme y de que yo no tenga negoçio ninguno ni nombre, sino que me ande echo bagamundo» ${ }^{66}$.

Dado que ese conflicto estaba poniendo en peligro la gestión de los negocios de Penamacor, este último se decantó por recurrir a la mediación del licenciado don Luis Enríquez en octubre de 1642. Parece que esa intervención fue considerada por Ferreirín como un cuestionamiento de su capacidad como administrador de las rentas, poniendo en entredicho su crédito ante la comunidad de mercaderes y negociantes hispalense. Así lo advertía el propio don Luis Enríquez al hacerse eco de la opinión de Ferreirín y de su madre doña Felipa Núñez:

su sobrino Antonio López Ferreyrín [...] está quejosso y aflijido porque como es moço y no save que el fruto de los parientes y amigos es amargo y de reprehensión, piensa que la de VMd no nace de aquella buena voluntad que yo aseguro le tiene VMd [...], la señora Doña Felipa siente por la reputación esto y él [Ferreirín] y su merced piensan que lo que entre nosotros pasa es un disfame público ${ }^{67}$.

Ese disfame público al que hacía referencia acabaría por hacerse realidad tras la destitución de Ferreirín en mayo de 1643, siendo sustituido por su rival Francisco Rodríguez Lameira y viéndose relegado a la atención de comisiones menores en las rentas de Penamacor ${ }^{68}$. Pasado un año doña Felipa todavía se lamentaba de las repercusiones de tal decisión en la reputación de su hijo:

66. Ibidem, carta de Antonio López Ferreirín (Sevilla) a Francisco Rodríguez Penamacor (Madrid), 15-7-1642.

67. AHN, Inquisición, leg. 3843, caja 1, carta de don Luis Enríquez (Sevilla) a Francisco Rodríguez Penamacor (Madrid), 11-10-1642.

68. A mediados de julio de 1644 Ferreirín se encontraba en La Coruña con objeto de gestionar diversos pleitos de la renta del azúcar en el Reino de Galicia. AHN, Inquisición, leg. 3839, caja 1, carta de Antonio López Ferreirín (La Coruña) a Francisco Rodríguez Penamacor (Madrid), 24-7-1644.

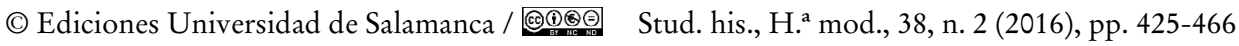


que Antonio tan onbre era para este negosio y para dar coenta de sí como los Lameiras pero ellos proquraron para aprovecharse desaqreditallo con VMd que tan presto se llevó de sus enbustes sin atender a más ni reparar en el discrédito del ynosente ${ }^{69}$.

Por tanto, este ejemplo permite constatar que la difusión de información mediante cartas desempeñaba un rol clave de cara a la evaluación de las reputaciones de agentes situados en localizaciones distantes. En función de esas valoraciones, hombres de negocios como Penamacor juzgaban si podían confiar, o no, en un determinado agente. De ahí que como consecuencia de las continuas críticas respecto a la incapacidad de Ferreirín para dirigir la administración sevillana, su tío Francisco Rodríguez Penamacor perdiese la fe en el mismo y se inclinase por un individuo más experimentado como Francisco Rodríguez Lameira. Una clara muestra de la estrecha relación del binomio confianza-reputación. Por otra parte, la retirada del poder para administrar las rentas a Ferreirín constituía una sanción informal en base a la reputación que podía conllevar graves consecuencias en la trayectoria de un determinado agente de negocios. Ferreirín no volvería a conseguir el preciado empleo de administrador o factor en los años siguientes y, de hecho, a mediados de 1647 continuaba desempeñando para distintos parientes comisiones de escaso aprovechamiento ${ }^{70}$.

Además de servir para establecer valoraciones de las reputaciones individuales, los intercambios epistolares posibilitaban llevar a cabo un continuo control mutuo entre agentes en base a las propias reputaciones. De ahí que autores como Avner Greif, Sebouh Aslanian, Ricardo Court o Francesca Trivellato, entre otros, hayan visto en la transmisión de información mediante cartas una suerte de mecanismos de control de la reputación que permitían juzgar la fiabilidad de cada agente ${ }^{71}$. Con ese fin la correspondencia era empleada para advertir sus

69. Ibidem, carta de Felipa Núñez (Sevilla) a Francisco Rodríguez Penamacor (Madrid), 26-7-1644.

70. Por ejemplo, como agente para el cobro de consignaciones en Utrera de los asientos de Enrique Núñez. AHN, Inquisición, leg. 3926, carta de Simón Rodríguez Núñez (Sevilla) a Francisco Rodríguez Penamacor (Madrid), 23-7-1647.

71. GreIf, A.: Institutions and the Path..., pp. 58-90; Aslanian, S.: From the Indian Ocean..., pp. 166-201. COURT, R.: «"Januensis Ergo Mercator”: Trust and Enforcement in the Business Correspondence of the Brignole Family», The Sixteenth Century Journal, vol. 35, 4, 2004, pp. 987-1003; Trivellato, F.: «Juifs de Livourne, Italiens de Lisbonne, hindous de Goa. Réseaux marchands et échanges interculturels à l'époque moderne», Annales. Histoire, Sciences Sociales, vol. 58, 3, 2003, pp. 581-603. Greif, Court y Aslanian, siguiendo postulados neoinstitucionalistas, ligan esos mecanismos de control basados en la reputación a coaliciones en cuanto que instituciones económicas informales conformadas por mercaderes de un mismo origen nacional o etno-religioso. Mientras tanto, en su estudio de las interacciones entre mercaderes de distintos contextos culturales o religiosos - no asimilables por tanto al referido concepto

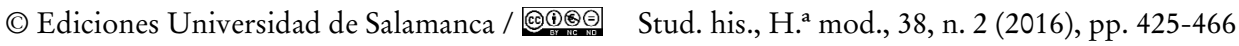


supuestas faltas y conminarles a aportar justificaciones coherentes para preservar su reputación, como puede observarse en el siguiente ejemplo. En enero de 1632 Diogo Barbosa Chacão, mercader portugués residente en Burdeos, respondía a una carta anterior de su primo Felipe Dias Guterres en la que este último habría expresado su descontento respecto a la calidad de un cargamento de cera. Parece ser que las raíces del desagrado de Felipe Dias procedían de la opinión que Juan Pérez de Beroiz, el intermediario vasco al que ambos recurrían en San Sebastián, le había transmitido acerca de dicha cera. A sabiendas de que su honradez estaba siendo puesta en duda, Diogo Barbosa defendería férreamente las bondades de su mercancía recurriendo incluso a supuestas opiniones de terceros:

e quanto ao que dis o senhor encomendeiro que se não vendia por dizerem ser roin, e mesclada com rasina, lhe pode VM escrever que digo eu que hé falso [...], foi vista de muita gente assi portugeses, como francesses, e todos dizerão que era bela fazenda, e que se avia de vender por ser de Landas que era da mesma bondade, e os portugeses que mandarão sera na mesma barca confesarão que era muito melhor a de VM.

Para hacer más verosímiles sus propios argumentos, Diogo Barbosa llegaba incluso a cuestionar la profesionalidad y fiabilidad de encomenderos como Beroiz, argumentando que «quem á de negocear por mãos de encomendeiros que não seja coisa propia tem trabalho». Además añadía que Felipe Dias no debería tener a dicho agente vasco «por bom encomendeiro» si no era capaz de vender la cera a pesar de la escasez de dicha mercancía en Medina de Rioseco ${ }^{72}$.

Las cartas permiten observar a su vez los negativos efectos a los que un determinado agente podía exponerse por una acción deshonesta. Así queda de manifiesto en la reacción del referido Diogo Barbosa tras el rechazo de António Enriques de Moura a pagar ciertas cantidades adeudadas a sus antiguos socios de compañía:

por huma de João do Porto soube o desaforamento do ladrão de António Enriques, e nenhuma maldade tentará que não creia de seo danado peito [...], eu há muito tempo que não falo com elle por me não querer pagar hum resto de poca importansia que me deve [...], e quando o Diabo o traga de lá que nos entenderemos com

de coalición- Trivellato trata de matizar las tesis neoinstitucionalistas refiriéndose a tales interacciones interculturales como relaciones informales sostenidas a través de los intercambios epistolares. Según Guillaume Calafat ello supone minusvalorar la importancia del contexto institucional en el que operaban dichos mercaderes. CALAFAT, G.: «Diasporas marchandes et commerce interculturel. Familles, réseaux et confiance dans l'economie de l'époque moderne», Annales. Histoire, Sciences Sociales, vol. 66, 2, pp. 513-531.

72. AHN, Inquisición, leg. 246, caja 2, carta de Diogo Barbosa Chacão (Burdeos) a Felipe Dias Guterres (Madrid), 19-1-1632.

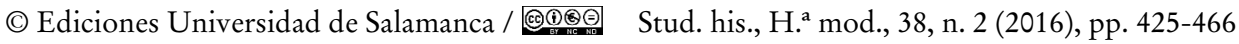


elle e lhe faremos dar quitação iudiciaria por rigor, ia que em brandura não quer faser coisa boa ${ }^{73}$.

La combinación de la difusión de malas opiniones como esta última con un posible pleito judicial minaría aún más la ya maltrecha reputación de António Enriques. De hecho, João do Porto amenazaba incluso con advertir sobre la perniciosa actitud del mismo a sus propios familiares: «conheçerão em Anveres e Paris seu cunhado quem ele hé» ${ }^{74}$. Todo ello podría limitar drásticamente las posibilidades de este mercader para ganarse en el futuro la confianza de otros individuos.

A raíz de estos ejemplos podría enunciarse que la preservación de una buena consideración instaría a cada actor económico a actuar honradamente respecto a sus pares o empleadores. Como ha tratado de probar Avner Greif desde premisas neoinstitucionalistas, los beneficios a largo plazo de dicha conducta eran superiores a los obtenidos a corto plazo mediante comportamientos incompetentes o fraudulentos, acompañados por lo general de diversas sanciones sociales o económicas $^{75}$. Así que las futuras consecuencias de las acciones honestas o deshonestas sobre la valoración de las reputaciones incidirían profundamente en el proceder de cada agente económico. De ahí que desde nuestra consideración las reputaciones actuasen como un resorte fundamental de la confianza, permitiendo a cada agente juzgar qué individuos eran fiables o no.

A simple vista puede parecer un modo de conducta sostenido sobre criterios racionalistas y, por tanto, guiados en exclusiva por el interés individual. Sin embargo, en estos comportamientos generados por el control de reputación mediarían una serie de valores normativos y prácticas culturales asociadas al estatus socioprofesional del hombre de negocios. Studnicki-Gizbert incluye entre dichos valores la honestidad, la franqueza, la munificencia y la humildad ${ }^{76}$. A ellos podríamos añadir otros como la competencia en los negocios o las prácticas de buena correspondencia referidas anteriormente. Todo hombre de negocios interesado en alcanzar y mantener una buena reputación debería por tanto respetar tales principios. De ahí que en ocasiones se estableciese una clara distinción respecto a individuos ajenos al mundo de los negocios y por tanto extraños a esas prácticas exclusivas. Como cuando Pantaleão Martines y Gaspar Rodrigues Vila Real advirtieran a Luis Fernández Pato, su corresponsal en Madrid, del riesgo inherente a los tratos financieros con fidalgos portugueses: «que letras de homens

73. Ibidem, carta de Diogo Barbosa Chacão (Burdeos) a Felipe Dias Guterres (Madrid), 2-8-1632.

74. Ibidem, carta de João do Porto (Burdeos) a Felipe Dias Guterres (Madrid), 3-8-1632.

75. GreIF, A.: «Reputation and Coalitions...», pp. 857-882.

76. Studnicki-Gizbert, D.: A Nation Upon the Ocean..., pp. 85-86.

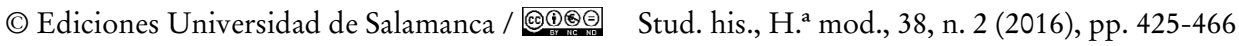


que não são de negócio ten isto que cobrão antes do tempo e não pagão se não coando queren» ${ }^{77}$.

Por tanto, se podría adscribir los comportamientos individuales dirigidos al sostenimiento de una buena reputación más bien a estrategias a medio camino entre el mero cálculo racional y la lógica de la estructura social de la que formaban parte $^{78}$. De modo que cada mercader u hombre de negocios gozaría de un margen de agencia que, no obstante, estaría influido por una serie de reglas o prácticas culturales asociadas a su ámbito social y profesional. Las interacciones sociales mediante las cartas permitían difundir esos valores y establecer los controles necesarios en base a la reputación. En ese sentido John Smail comprobó cómo los mercaderes ingleses del siglo XVIII empleaban en sus cartas una serie de códigos comunes en forma de «lenguaje del honor», mediante los cuales proyectaban su propia reputación a la vez que invocaban la de los demás con el fin de exhortarles a mantener su honestidad ${ }^{79}$. De ahí que Craig Muldrew se refiriese a la reputación como una suerte de moneda en un sistema de circulación lingüístico o retórico ${ }^{80}$. Por todo ello es posible afirmar que la construcción de las reputaciones entre agentes separados por distancias considerables era resultado de la combinación de información y valores culturales a través de las cartas. De ese modo se transmitían en el seno de esas redes egocentradas en cuanto que conjuntos de relaciones interpersonales, permitiendo establecer lazos de confianza entre los individuos que conformaban dichas redes.

\section{LA REPUTACIÓN COMO CRITERIO DE SELECCIÓN DE AGENTES}

A partir de las premisas anteriores, una de las hipótesis planteadas en este trabajo es que las consideraciones en torno a la reputación incidían profundamente en la selección o reclutamiento de corresponsales, factores o agentes comisionados. Podría argüirse que tal proposición minusvalora el papel desempeñado por la

77. AHN, Inquisición, leg. 3793, carta de Pantaleão Martines y Gaspar Rodrigues Vila Real (Lisboa) a Luis Fernández Pato (Madrid), 21-1-1634. En una carta anterior los susodichos ya le habían aconsejado lo siguiente: «disemos que se não meta com fidalgos que hé má gente en espesial desta terra». Ibidem, carta de Pantaleão Martines y Gaspar Rodrigues Vila Real (Lisboa) a Luis Fernández Pato (Madrid), 10-1-1634.

78. Paul McLean considera que las acciones individuales relacionadas con la búsqueda de patronazgo en la Florencia renacentista también son resultado de estrategias culturales expresadas mediante palabras a través de las interacciones epistolares. McLEAn, P. D.: The Art of the Network..., pp. 33-34.

79. Smail, J.: «Credit, Risk and Honor in Eighteenth-Century Commerce», Journal of British Studies, vol. 44, 3, 2005, pp. 439-456.

80. Muldrew, C.: The Economy of Obligation..., pp. 149-151.

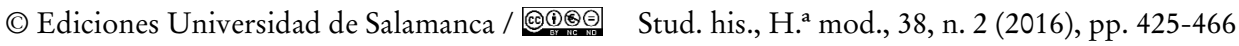


familia, o el origen nacional y etno-religioso común, como criterios de preferencia para escoger con quién sostener negocios. A pesar de ello, aquí pretendemos relativizar -pero en absoluto refutar- la influencia de la endogamia, tanto familiar como nacional, en la selección de agentes en localizaciones distantes, siguiendo así la estela de recientes estudios ${ }^{81}$.

En cuanto a la familia, no cabe duda de que los lazos de parentesco (consanguíneos o políticos) han sido generalmente tenidos por sinónimo de confianza durante la Edad Moderna. Los vínculos de solidaridad emanados de las obligaciones inherentes a la parentela explican que esta se convirtiese en ocasiones en el núcleo básico del reclutamiento de agentes. Así, desde principios de 1644 Francisco López Capadocia confió en su primo Gerónimo García el importantísimo empleo de factor en Sevilla para su asiento de provisión de Ceuta ${ }^{82}$. Mientras tanto, a partir de diciembre de 1648 Manuel Núñez Mercado y Juan Rodríguez Núñez contarían con su hermano Baltasar Rodríguez Núñez como tesorero de la renta de la seda de Granada. Del mismo modo que ya recurrían a sus primos Baltasar Rodríguez de Castro y Antonio Ribero de Paiva como agentes para el cobro de las consignaciones de sus asientos.

Sin embargo, desde el punto de vista cuantitativo estos familiares solo constituían una pequeña proporción del conjunto total de interacciones sociales sostenidas tanto por Francisco López Capadocia como por los hermanos Manuel Núñez Mercado y Juan Rodríguez Núñez. Así puede observarse en las Tablas 1 y 2 del anexo incluido al final de este artículo. Por ejemplo, solo 6 de los 46 corresponsales que remitieron cartas a Capadocia entre enero y agosto de 1644 poseían algún vínculo de parentesco con el mismo. Un porcentaje escaso (13\%), aunque mayor si se tiene en cuenta que dichos parientes remitieron 52 cartas de un total de $231(22,5 \%)$. Más grande fue el peso de los parientes en la correspondencia de los hermanos Mercado para los meses de diciembre de 1648 y enero de 1649, contabilizando 10 individuos de entre sus 51 correspondientes (19,6\%), que a su vez remitieron 61 de las 148 cartas $(41,2 \%)$ recibidas por los mismos. Hay que tener en cuenta que el limitado peso cuantitativo de los parientes en estas redes egocentradas bien podría deberse a las propias limitaciones de la parentela, ya

81. Ribeiro, A. S.: «A endogamia em redes mercantis da "Primeira Idade Global". O caso da rede de Simon Ruiz (1553-1597)», História. Revista da FLUP Porto, IV Série, vol. 2, 2012, pp. 23-40; STRum, D.: The Sugar Trade. Brazil, Portugal, and the Netherlands (1595-1630). Stanford, 2013, pp. 466-476.

82. El poder notarial recibido por Gerónimo García como factor de Capadocia puede verse en AHN, Inquisición, leg. 4030, caja 2, «Badajoz. 1646. Poder del asentista a Gerónimo García. Papeles para la saca del trigo de Almendralejo», 30-5-1644.

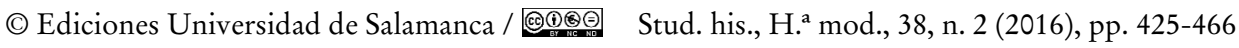


fueran de carácter demográfico, geográfico o profesional. No obstante, siguiendo la teoría de la «fuerza de los lazos débiles» de Mark Granovetter ello se explicaría también por el hecho de que estos hombres de negocios fueran proclives a diversificar los riesgos y acceder a nuevas fuentes de información a través de individuos no pertenecientes a su círculo más próximo de parientes o amigos ${ }^{83}$.

Por otra parte resulta obvio que los parientes no tenían por qué ser fiables per se. Por ejemplo, a finales de 1631 Jacinto Gomes se refería en durísimos términos respecto a Manuel Nunes Gomes, su cuñado y corresponsal en Málaga, calificándolo de «grandisimo velhaco malisioso e malvado» por no responder a sus cartas y llegando incluso a cuestionar su moralidad: «que elle ja não conheçe mais que as suas mulatas con quen está amansebado e ese hé todo o seu parentesco» ${ }^{84}$. Meses después Jacinto volvía a manifestar de nuevo su enojo respecto a la actitud de su cuñado, amenazando incluso con romper la correspondencia con el mismo: «dito me escreve humas cartas de muita desconfiansa que me não atrevo a lhe escrever nen con elle quero mais que escrever» ${ }^{85}$. De ahí se explica que los controles en base a la reputación que antes analizáramos se hicieran extensibles a los propios familiares. Ello queda de manifiesto en las excusas presentadas por el propio Jacinto Gomes tras ser reprendido por su primo Felipe Dias Guterres a causa de la escasa calidad de ciertos lienzos remitidos: «serto que me espanto de VM diserme que ando sempre buscando bromas para remeter sendo que os lensoins airados de ordinario os mandão a essa Corte e hé fasenda boa» ${ }^{86}$.

También se puede relativizar la afirmación de que los agentes procedentes de un mismo grupo nacional o etno-religioso fueran percibidos como más fiables. Del mismo modo que con los parientes, o bien no era posible contar con paisanos en todos los lugares donde fuesen necesarios sus servicios, o bien estos no eran considerados lo suficientemente íntegros o aptos. Aunque la consulta de los epistolarios de los cinco hombres de negocios aquí estudiados permite corroborar

83. Según Granovetter la posesión de «lazos débiles», vínculos con individuos ajenos al ámbito social más próximo, posibilitaría el acceso a fuentes de información e ideas procedentes de otras partes del sistema social. Frente a ellos se situarían unos «lazos fuertes»-parientes y amigos- que, si bien más cooperativos y accesibles, solo permitían alcanzar información e ideas ya conocidas. GranovetTer, M.: «The Strength of Weak Ties: A Network Theory Revisited», Sociological Theory, vol. 1, 1983, pp. 201-233.

84. AHN, Inquisición, leg. 246, caja 2, carta de Jacinto Gomes (Nantes) a Felipe Dias Guterres (Madrid), 17-12-1631.

85. Ibidem, carta de Jacinto Gomes (Nantes) a Felipe Dias Guterres (Madrid), 25-8-1632.

86. AHN, Inquisición, leg. 247, caja 1, carta de Jacinto Gomes (Nantes) a Felipe Dias Guterres (Madrid), 12-1-1633. En portugués la palabra «broma» es asimilable a ordinario o de mala calidad.

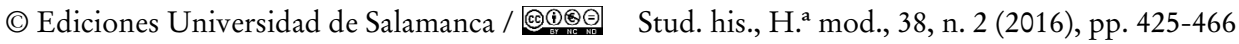


que la mayor parte de sus corresponsales y agentes eran igualmente portugueses, entre ellos se contaban también individuos de distinto origen nacional. Ese sería el caso de los encomenderos vascos a los que algunos de estos negociantes portugueses recurrieron en puertos como los de Bilbao o San Sebastián para la remisión o recepción de mercancías respecto a corresponsales situados en mercados del norte de Europa. Así, tanto Manuel Núñez Mercado como Luis Fernández Pato contaron en distintos momentos de las décadas de 1630 y 1640 con los servicios de Francisco Beroiz Fagola en San Sebastián, mientras que Felipe Dias y sus parientes en Francia hicieron lo propio con Francisco de Landa en Bilbao y Juan Pérez de Beroiz en San Sebastián entre 1632 y $1634^{87}$. Algo similar se prueba en el hecho de que en el verano de 1644 Francisco Rodríguez Penamacor decidiese enviar a Cádiz y Sevilla a un agente castellano, don Juan de Quiñones y Sandoval, con la comisión de fiscalizar las cuentas de los administradores de sus rentas en dichas ciudades: los hermanos Francisco y Jorge Rodríguez Lameira, portugueses ${ }^{88}$.

Mediante el análisis cualitativo de dichos epistolarios se puede corroborar que ya fuera respecto a parientes, paisanos o individuos de distinta procedencia nacional o etno-religiosa, las valoraciones en torno a la reputación mediaban en la búsqueda y reclutamiento de agentes económicos fiables. Ese parece haber sido el criterio escogido por Manuel Nunes Gomes a principios de 1630 para solicitar a Felipe Dias Guterres referencias de algún mercader genovés de confianza en Cartagena: «Se VM tuviere aí notisia de algún genovés rico i pontoal estimaría conoserle em Cartagena para correr con él» ${ }^{89}$. No sería la única vez que Manuel Nunes Gomes fiara en la información acerca de la reputación la trascendental decisión de confiar o no en determinados individuos, como cuando cuatro años después preguntase por algún encomendero vasco para remitir dinero a Francia: «estimaría saber qué encomendero biscaíno brilla aí oi más para remitir un poco de dinero que me importa, avísemelo VM». En la misma carta también pretendía

87. En 1655 Francisco Beroiz Fagola figuraba también como correspondiente en San Sebastián de varios mercaderes judíos sefarditas de Ámsterdam. IsRAEL, J. I.: Empires and Entrepots. The Dutch, the Spanish Monarchy and the Jerws, 1585-1713. Londres-Ronceverte, 1990, pp. 410-415. El recurso a encomenderos vizcaínos pudo deberse al particularismo jurídico-institucional de los territorios vascos, materializado a través de sus respectivos fueros. Sobre la influencia de los mismos en las interacciones mercantiles sostenidas entre mercaderes bilbaínos e ingleses durante el siglo XviII, Lamikiz, X.: Trade and Trust..., pp. 29-39.

88. AHN, Inquisición, leg. 3839, caja 1, carta de don Juan de Quiñones y Sandoval (Cádiz) a Francisco Rodríguez Penamacor (Madrid), 24-7-1644. AHN, Inquisición, leg. 3843, caja 1, carta de don Juan de Quiñones y Sandoval (Cádiz) a Francisco Rodríguez Penamacor (Madrid), 31-7-1644.

89. AHN, Inquisición, leg. 246, caja 2, carta de Manuel Nunes Gomes (Málaga) a Felipe Dias Guterres (Madrid), 5-2-1630.

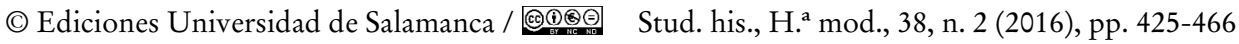


saber acerca de confiteros de prestigio en Madrid para la venta de ciertas cantidades de azúcar brasileño: «quisiera me diera VM a conoser aí con algunos confiteros de buena opinión assí de asienda como de virtudes porque me allo con una partida dellos [azúcares] del Río de Janeiro» ${ }^{90}$.

Existen otros ejemplos igualmente representativos. Tras lograr el arriendo de la renta de la seda de Granada en diciembre de 1648, los hermanos Manuel Núñez Mercado, Juan Rodríguez Núñez y Baltasar Rodríguez Núñez necesitaban reclutar agentes para su gestión ${ }^{91}$. Una vez asumida la dirección del negocio por Baltasar Rodríguez, este garantizó a su hermano Juan que se encargaría de contratar individuos de buena consideración para ocuparse de las cobranzas y otros menesteres a lo largo del Reino de Granada: «aquá ay gente arta. Y se buscará a toda satisfación y se yrán conosiendo los buenos y alguno que no lo yziere bien se yrá con Dios» ${ }^{92}$. En relación con la administración de dicha renta en Málaga, Manuel Núñez Mercado señalaba por esas mismas fechas que «es menester persona de toda confiança en Málaga y sus lugares» ${ }^{93}$. Se comprueba de nuevo la influencia desempeñada por la reputación en cuanto que criterio esencial para la selección de agentes fiables.

Lo mismo se desprende de la consulta del epistolario de Francisco López Capadocia entre enero y agosto de 1644, periodo durante el cual se hallaba negociando con la Junta de Presidios la contratación del asiento de provisión de Ceuta, que finalmente se materializó en mayo de $1644^{94}$. Este caso permite evaluar el papel de las referencias de recomendación y de presentación, no solo como instrumento para transmitir valoraciones sobre la reputación, sino también como medio para evaluar el reclutamiento de nuevos agentes en distintos ámbitos geográficos ${ }^{95}$. Por

90. AHN, Inquisición, leg. 247, caja 2, carta de Manuel Nunes Gomes (Málaga) a Felipe Dias Guterres (Madrid), 14-3-1634.

91. La renta se tomó por un periodo de diez años y un precio de 41.000 .000 maravedíes anuales. AGS, CCGG, leg. 142, Asiento tomado con Juan Rodríguez Núñez y Baltasar Rodríguez Núñez sobre el arrendamiento de la renta de la seda de la ciudad de Granada y su Reino, 31-12-1648.

92. AHN, Inquisición, leg. 3945, carta de Baltasar Rodríguez Núñez (Granada) a Juan Rodríguez Núñez (Madrid), 8-12-1648.

93. Ibidem, carta de Manuel y Jorge Núñez Mercado (Sevilla) a Juan Rodríguez Núñez (Madrid), 8-12-1648.

94. El asiento fue contratado por un periodo de tres años contados desde enero de $1644 \mathrm{y}$ el montante total del mismo, tanto en moneda como en especie, ascendió a 796.127 reales de plata y 2.429.912 reales de vellón. AHPM, protocolo 5411, Francisco de Yanguas, 9-5-1644, fol. $81 \mathrm{r}-86 \mathrm{v}$.

95. Así lo comprueba Trivellato en el caso de la familia Ergas-Silvera de Livorno. TrivelLato, F.: The Familiarity of Strangers..., pp. 182-183.

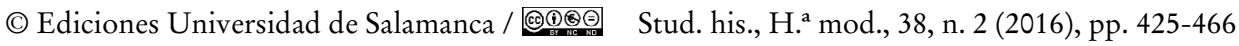


ejemplo, nada más hacerse eco de los rumores acerca de que Capadocia se haría con el negocio de la provisión de Ceuta, el anterior contratador del asiento -el también portugués Francisco Rodríguez Villarreal- ofreció tanto su persona como la de alguno de sus hijos para el empleo de factor en el presidio norteafricano:

estoi entendiendo que con el favor de Dios a de tomar VMd este provimiento de Zeuta [...] y buelvo aser [a] VMd recuerdo que si VMd lo toma me a de aser merced de dar aquella plaza para un hijo mío o para mí, que naide lo aser [...] con más boluntad ni fidelidad que yo o mis hijos, que qualquiera dellos son capases asello96.

Igualmente, Manuel Mendes de Oliveira se puso a disposición de Capadocia tras ser informado de la próxima firma del asiento. Dada la necesidad de un agente comisionado en Cádiz, Mendes de Oliveira se presentaba a sí mismo como candidato ideal para dicho empleo asegurando que se pondría enteramente al servicio de Gerónimo García, el factor de Capadocia en Sevilla: «serán sienpre sus órdenes mui asertadas e fio de mí que las seguiré al pie de la letra daquí en adelante com avizo de $\mathrm{VM}{ }^{{ }^{97}}$. De uno u otro modo, mediante esas alusiones personales tanto Villarreal como Mendes de Oliveira pretendían influir en la futura decisión de Capadocia. Aunque los Villarreal no tendrían éxito en su pretensión no sucedería lo mismo con Mendes de Oliveira, ya que a finales del mes de julio le fue confirmado su nombramiento como agente en Cádiz ${ }^{98}$.

Algo similar ocurría con el empleo de las cartas para efectuar recomendaciones de terceros. Dado que a la altura de mayo de 1644 Capadocia no se había decantado todavía por ninguna persona para conducir su negocio en Ceuta, el capitán Sebastião Lopes Pães, miembro de la guarnición del presidio, aprovechó la ocasión para presentar una sugerencia asegurando que no acostumbraba a hacerlo salvo para «aproveitamento, crédito, e reputação de meus amigos». De ese modo el capitán exponía la necesidad de contratar a un individuo natural de la plaza, que fuese además «pessoa de respeito de proçedimentos e verdade, bem quisto com tudos». Proponía para tal efecto a António da Costa Lopes, respecto a quien se deshacía en elogios:

que perguntando VM por seu nome achará que digo pouco, e que toda esta çidade se dará por tão pagua com a eleição que lhe pareçerá que correndo isto por elle

96. AHN, Inquisición, leg. 3887, caja 2, carta de Francisco Rodríguez Villarreal (Sevilla) a Francisco López Capadocia (Madrid), 2-2-1644.

97. Ibidem, carta de Manuel Mendes de Oliveira (Sanlúcar de Barrameda) a Francisco López Capadocia (Madrid), 30-4-1644.

98. AHN, Inquisición, leg. 3887, caja 1, carta de Manuel Mendes de Oliveira (Sanlúcar de Barrameda) a Gerónimo García (Sevilla), 31-7-1644.

(C) Ediciones Universidad de Salamanca / @@ Stud. his., H. ${ }^{a}$ mod., 38, n. 2 (2016), pp. 425-466 
lhe sobeia tudo porque todas as partes cabães que se requerem tem, não digo eu só isto se não para tudo o que se lhe encarguar, porque a verdade, christandade, bom pesa de mais, bem quisto com todos, lindo modo, e traça com todos [...] que fas ventagem a muitos ${ }^{99}$.

Al contrario que el capitán Lopes Pães, Gerónimo García se oponía al nombramiento de un natural de Ceuta recurriendo para ello a la opinión del propio almojarife de la plaza: "Juan Pereira [Gutiérrez] me dise que no ai que fiar en ninguno de Seuta que son todos ladrones que él fue fator muchos años y save bien lo necesario» ${ }^{100}$. Para evitar tales males Gerónimo García propondría como candidato a su sobrino Diego López Pereira, quien había sido administrador en la renta de las salinas de Andalucía tierra adentro. Sin embargo, el último rechazaría la oferta de Capadocia solicitando un salario superior al inicialmente ofrecido ${ }^{101}$. De modo que a principios de agosto Capadocia parecía resuelto a confiar el negocio a una persona de la propia Ceuta. De ahí que de nuevo Gerónimo García le advirtiera de los riesgos de tal decisión:

Veo cómo VMd se determina a inviar poder para que persona de la plasa asista allí a lo necesario, [...] mas ya e dicho muchas otras veses es errarlo y todos los que an entendido este género disen lo mesmo [...] y asta Tomé Alvares dise que conviene persona de fuera ${ }^{102}$.

Tanto Sebastião Lopes Pães como Gerónimo García pretendían incidir con sus referencias acerca de la reputación de terceros en la elección de Francisco López Capadocia, quien necesitaba del criterio de otros colaboradores para encontrar un agente de confianza para Ceuta. Se observa así de forma clara la influencia de la difusión de información mediante cartas en la construcción de las reputaciones personales. En este caso concreto Capadocia se dejaría guiar finalmente por las prevenciones de Gerónimo García, decantándose por Diego López Pereira

99. Ibidem, carta de Sebastião Lopes Pães (Ceuta) a Francisco López Capadocia (Madrid), 16-5-1644.

100. Ibidem, carta de Gerónimo García (Sevilla) a Francisco López Capadocia (Madrid), 5-7-1644.

101. Diego López Pereira refería que solo aceptaría el empleo de factor por 500 ducados (5.500 reales) anuales y no por los 4.000 reales ofertados inicialmente por Capadocia a causa del aislamiento de Ceuta respecto al territorio peninsular y de la reciente caída de Tánger en manos de los rebeldes portugueses. AHN, Inquisición, leg. 3887, caja 1, carta de Diego López Pereira (Baena) a Francisco López Capadocia (Madrid), 28-6-1644.

102. Ibidem, carta de Gerónimo García (Sevilla) a Francisco López Capadocia (Madrid), 2-8-1644.

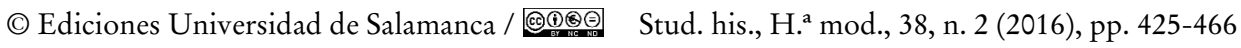


como su factor en Ceuta ${ }^{103}$. Una decisión influida sin duda por la mala reputación atribuida por García a los habitantes de la plaza norteafricana, hecho que habría impedido a Capadocia confiar buena parte del porvenir de su asiento en un natural de dicho presidio.

Aunque las valoraciones sobre la reputación no tuvieran por qué incidir directamente en la selección definitiva de determinados agentes, tanto el recurso a las cartas para solicitar información acerca de individuos fiables como el uso de las mismas como vehículo de transmisión de referencias personales o de terceros prueban la estrecha relación de la reputación con la trascendental decisión de confiar en otros actores económicos. De modo que el conocimiento de la buena o mala reputación de cada agente permitía hacer frente al riesgo inherente a fiar determinados negocios a individuos que, a causa de la distancia, no podían ser monitorizados personalmente.

\section{Conclusiones}

Este artículo ha pretendido profundizar en el estudio de una cuestión sumamente crucial en el mundo de los negocios durante la Edad Moderna, la de la articulación de la confianza entre personas separadas por el espacio geográfico. Con ese fin se ha recurrido a una perspectiva de redes mediante la cual se ha llevado a cabo el análisis cualitativo de las interacciones sociales sostenidas por cinco hombres de negocios portugueses residentes en Madrid en las décadas centrales del siglo Xvi con los distintos individuos que habrían conformado sus redes egocentradas. Para ello la correspondencia epistolar se muestra una fuente documental fundamental no solo de cara a la reconstrucción de tales redes egocentradas, sino especialmente para el examen de los factores en que descansaba la confianza entre sus conformantes. De ese modo se ha podido comprobar la importancia de la transmisión de información mediante las cartas a la hora de reducir los riesgos y la incertidumbre asociados al desarrollo de actividades económicas con individuos situados en localizaciones distantes. A su vez, se ha corroborado el papel desempeñado por una serie de códigos o valores culturales empleados en las cartas en la generación de certidumbre y confianza respecto a los receptores de las mismas. Esos valores eran plasmados tanto en el uso de una etiqueta de cortesía como en el respeto de una serie de prácticas

103. En su primera causa inquisitorial Francisco López Capadocia incluyó en su declaración de enemigos capitales a Diego López Pereira, a quien refirió como su antiguo factor en Ceuta. AHN, Inquisición, leg. 161, exp. 5, Proceso de fe contra Francisco López Capadocia (16531655), fol. 28r-29v.

(C) Ediciones Universidad de Salamanca / ㅛ Stud. his., H. ${ }^{a}$ mod., 38, n. 2 (2016), pp. 425-466 
de buena correspondencia. Estas últimas se basaban en el mantenimiento de la reciprocidad y la presteza en el intercambio de cartas, así como en la claridad del contenido de las mismas.

La combinación de información y prácticas culturales en las cartas resultaba además elemental en la construcción de las valoraciones sobre las reputaciones individuales. La reputación constituía una consideración clave en la cimentación de la confianza interpersonal al permitir establecer juicios sobre la fiabilidad de cada agente económico. De ahí que la conservación de la reputación resultase fundamental para los mismos, pues su deterioro podía conducir al ostracismo en un determinado emplazamiento o círculo social. Igualmente, se ha verificado cómo las interacciones epistolares eran empleadas como mecanismos de control de la reputación permitiendo transmitir información y juicios sobre las acciones o comportamientos de ciertos individuos. Así como también para conminar a los remisores de las cartas a sostener su credibilidad cuando esta fuera puesta en entredicho. Ese control de las reputaciones estaba estrechamente ligado a una serie de principios asociados al estatus socioprofesional del hombre de negocios, unos fundamentos difundidos en el seno de estas redes egocentradas mediante las cartas.

Por último, el análisis de la construcción de la relaciones de confianza a través de la reputaciones nos ha llevado a llamar la atención sobre el rol desempeñado por la últimas en cuanto que criterio de selección o reclutamiento de corresponsales, factores o agentes. Con tal pretensión hemos tratado de demostrar que esas consideraciones respecto a la reputación podían llegar a ser privilegiadas por encima de los lazos de parentesco o paisanaje, sin cuestionar por supuesto la influencia ejercida por tales vínculos. Ello queda de manifiesto no solo a través del uso de las cartas para solicitar referencias respecto a agentes de buena consideración, sino también en el empleo de las mismas como mecanismos de presentación personal o de recomendación de terceros. Por consiguiente, el estudio cualitativo de esos conjuntos de interacciones sociales desentrañados a través de las epistolarios de ciertos hombres de negocios portugueses ha permitido corroborar la estrecha relación de la información y la reputación con la gestación y sostenimiento de la confianza. Un elemento primordial en el día a día de las operaciones económicas durante el periodo moderno. 

EN REDES SOCIALES DE HOMBRES DE NEGOCIOS PORTUGUESES

\section{ANEXO}

Tabla 1. Cartas recibidas por Francisco López Capadocia (enero - agosto 1644) AHN, Inquisición, leg. 3887

\begin{tabular}{|c|c|c|c|}
\hline $\begin{array}{l}\text { Remitente(s) } \\
\text { [en cursiva: parientes] }\end{array}$ & Origen $\left(\mathrm{y} \mathrm{n}^{\circ}\right)^{\circ}$ de cartas & Nación & Relación \\
\hline Diego López Pereira & Baena (1) & Portugués & Futuro factor \\
\hline Licenciado Francisco Vieira Matosso & Cádiz (8) & Portugués & Corresponsal \\
\hline $\begin{array}{l}\text { Juan Rodríguez Penso y Antonio de } \\
\text { Fonseca }\end{array}$ & Cádiz (1) & Portugueses & - \\
\hline Jacob Saportas & Cartagena (4) & Judío oraní & Corresponsal \\
\hline Nicolás de Villalba Estrada & Cartagena (6) & Castellano & Corresponsal \\
\hline $\begin{array}{l}\text { D. Lope da Cunha, conde de Asentar } \\
\text { [consejero en la Junta de Presidios] }\end{array}$ & Ceuta (1) & Portugués & $\begin{array}{l}\text { Corresponsal } \\
\text { político }\end{array}$ \\
\hline Fray António de Magalhães & Ceuta (2) & Portugués & Amigo \\
\hline $\begin{array}{l}\text { D. Juan Fernández de Córdoba, marqués } \\
\text { de Miranda de Auta } \\
\text { [gobernador de Ceuta, h. 1644] }\end{array}$ & Ceuta (2) & Castellano & $\begin{array}{l}\text { Corresponsal } \\
\text { político }\end{array}$ \\
\hline Capitán Sebastião Lopes Pães & Ceuta (3) & Portugués & Corresponsal \\
\hline Gaspar Rodríguez Fraga & Granada (1) & Portugués & Corresponsal \\
\hline Diogo da Costa Fonseca & Huéscar (1) & Portugués & Agente \\
\hline Antonio Fernández Videira & Jaén (22) & Portugués & Agente \\
\hline Diego Fernández Cáceres & Jaén (1) & Portugués & - \\
\hline Manuel Enriques Valentim & Jaén (1) & Portugués & - \\
\hline D. Gaspar de Villarroel & Lopera (1) & Castellano & - \\
\hline Francisco Gómez & $\begin{array}{l}\text { Lopera }(3) \\
\text { Porcuna (7) } \\
\text { Torredonjimeno (7) }\end{array}$ & Portugués & Agente \\
\hline Antonio Gómez Núñez & Málaga (15) & Portugués & Agente \\
\hline Antonio López Moreno & Málaga (5) & Portugués & Corresponsal \\
\hline Duarte Méndez & $\begin{array}{l}\text { Málaga (9) } \\
\text { Sevilla (1) }\end{array}$ & Portugués & Factor \\
\hline $\begin{array}{l}\text { Francisco Rodríguez Villarreal (de } \\
\text { Málaga) }\end{array}$ & Málaga (4) & Portugués & Corresponsal \\
\hline Gabriel Lorenzo & Málaga (1) & Portugués & Agente \\
\hline García Fernández & Málaga (13) & Portugués & Agente \\
\hline Gonzalo Díaz Villarreal & Málaga (2) & Portugués & - \\
\hline Luis Antonio de Morales & Málaga (1) & Portugués & \\
\hline $\begin{array}{l}\text { D. Marcos de Peñavera } \\
\text { [veedor de armadas, fortificaciones y } \\
\text { artillería de la costa de Granada] }\end{array}$ & Málaga (2) & Castellano & $\begin{array}{l}\text { Corresponsal } \\
\text { político }\end{array}$ \\
\hline Pedro Fernández Cáceres & Málaga (20) & Portugués & Agente \\
\hline
\end{tabular}


ÁLVARO SÁNCHEZ DURÁN

INFORMACIÓN Y REPUTACIÓN EN EL SIGLO XVII: LA CONSTRUCCIÓN DE LA CONFIANZA EN REDES SOCIALES DE HOMBRES DE NEGOCIOS PORTUGUESES

\begin{tabular}{|l|l|l|l|}
\hline \multicolumn{1}{|c|}{ Remitente(s) } & \multicolumn{1}{|c|}{ Origen (y n. ${ }^{\circ}$ ) de cartas } & \multicolumn{1}{|c|}{ Nación } & \multicolumn{1}{c|}{ Relación } \\
\hline Sebastián Lorenzo parientes] & Málaga (1) & Portugués & Agente \\
\hline Ana Rodríguez & Medina de Rioseco (1) & Portuguesa & - \\
\hline D. Juan de Sierra Cardoso & Medina de Rioseco (3) & - & Agente \\
\hline Juan Núñez de Paz & Murcia (1) & Portugués & - \\
\hline Capitán D. Juan de Negrete Sarmiento & Orán (4) & Castellano & Corresponsal \\
\hline Pedro Fernández Méndez & $\begin{array}{l}\text { Orense (9) } \\
\text { Santiago (1) }\end{array}$ & Portugués & Corresponsal \\
\hline D. Antonio de Silva & Orgaz (2) & Portugués & Agente \\
\hline Manuel Mendes de Oliveira & $\begin{array}{l}\text { Sanlúcar de Barra- } \\
\text { meda (7) }\end{array}$ & Portugués & Agente \\
\hline Francisco Fernández & Santiago (5) & Portugués & Corresponsal \\
\hline Gaspar Méndez & Santiago (2) & Portugués & Corresponsal \\
\hline Antonio Cardoso Laínez & Segovia (2) & Portugués & Corresponsal \\
\hline $\begin{array}{l}\text { Antonio Nunes Henriques y Henrique } \\
\text { Fernandes Vieira }\end{array}$ & Sevilla (1) & Portugueses & - \\
\hline Baltasar Luis Villarreal & Sevilla (1) & Portugués & Corresponsal \\
\hline $\begin{array}{l}\text { Francisco Rodríguez Villarreal (de Sevilla) } \\
\text { [asentista de Ceuta h. 1643] }\end{array}$ & Sevilla (9) & Portugués & Corresponsal \\
\hline Gerónimo García & Sevilla (28) & Portugués & Factor \\
\hline Diego Gómez & Toledo (7) & Portugués & Agente \\
\hline Domingo Francisco de Ledesma & Zaragoza (1) & - & - \\
\hline Manuel López & Zaragoza (1) & - & - \\
\hline
\end{tabular}

Tabla 2. Cartas recibidas por Manuel Núñez Mercado y Juan Rodríguez Núñez (diciembre 1648 - enero 1649) AHN, Inquisición, leg. 3945 y leg. 3951

\begin{tabular}{|l|l|l|l|}
\hline \multicolumn{1}{|c|}{$\begin{array}{c}\text { Remitente(s) } \\
\text { [en cursiva: parientes] }\end{array}$} & Origen (y n. ${ }^{\circ}$ ) de cartas & \multicolumn{1}{|c|}{ Nación } & \multicolumn{1}{|c|}{ Relación } \\
\hline D. Antonio Lameira & Alcalá de Henares (1) & Portugués & - \\
\hline Manuel de Carvajal & $\begin{array}{l}\text { Almuñécar (1) } \\
\text { Granada (1) }\end{array}$ & - & Agente \\
\hline Antonio Ribero de Paiva & $\begin{array}{l}\text { Badajoz (1) } \\
\text { Mérida (7) }\end{array}$ & Portugués & Agente \\
\hline Juan Román Barrena & Badajoz (1) & Castellano & - \\
\hline $\begin{array}{l}\text { D. Diego Mexía de Guzmán, marqués de } \\
\text { Leganés } \\
\text { [maestre general del Ejército de Badajoz] }\end{array}$ & Badajoz (1) & Castellano & $\begin{array}{l}\text { Corresponsal } \\
\text { político }\end{array}$ \\
\hline D. Alonso del Pozo Bustamante & Cáceres (2) & Castellano & Corresponsal \\
\hline
\end{tabular}

(C) Ediciones Universidad de Salamanca / 요 Stud. his., H. ${ }^{a}$ mod., 38, n. 2 (2016), pp. 425-466 
ÁLVARO SÁNCHEZ DURÁN

INFORMACIÓN Y REPUTACIÓN EN EL SIGLO XVII: LA CONSTRUCCIÓN DE LA CONFIANZA EN REDES SOCIALES DE HOMBRES DE NEGOCIOS PORTUGUESES

\begin{tabular}{|c|c|c|c|}
\hline $\begin{array}{c}\text { Remitente(s) } \\
\text { [en cursiva: parientes] }\end{array}$ & Origen $\left(\mathrm{y} \mathrm{n} .{ }^{\circ}\right)$ de cartas & Nación & Relación \\
\hline $\begin{array}{l}\text { D. Gonzalo de Carvajal Ulloa } \\
\text { [regidor perpetuo de Cáceres] }\end{array}$ & Cáceres (2) & Castellano & - \\
\hline Juan Martínez Muñoz & Cuenca (5) & Castellano & Agente \\
\hline Baltasar Rodríguez Núñez & Granada (11) & Portugués & Socio \\
\hline Diego Gómez Carlos & Granada (1) & Castellano & - \\
\hline Fernando Gómez Díaz & Granada (2) & Portugués & Agente \\
\hline Enrique Fernández Torres & Granada (1) & Portugués & Corresponsal \\
\hline D. Ignacio de Reinoso & Granada (1) & Castellano & Agente \\
\hline Juan Rodríguez Gómez & Granada (1) & Portugués & Agente \\
\hline Pedro Viejo Blanco & Granada (1) & Castellano & Agente \\
\hline Rafael de Amezquita & Granada (2) & Portugués & Agente \\
\hline $\begin{array}{l}\text { D. Tomás de Valdés } \\
\text { [alcalde de hijosdalgo de la Real Chancillería } \\
\text { de Granada] }\end{array}$ & Granada (1) & Castellano & $\begin{array}{l}\text { Juez conser- } \\
\text { vador subde- } \\
\text { legado }\end{array}$ \\
\hline Rodrigo Muñiz de Miranda & Illescas (1) & Portugués & Corresponsal \\
\hline Baltasar Rodríguez de Castro & $\begin{array}{l}\text { Llerena (6) } \\
\text { Trujillo (5) }\end{array}$ & Portugués & Agente \\
\hline Juan Ponce & Llerena (1) & Castellano & - \\
\hline Martín Pinto & Llerena (1) & - & - \\
\hline $\begin{array}{l}\text { Manuel Núñez Mercado y Jorge Núñez } \\
\text { Mercado }\end{array}$ & $\begin{array}{l}\text { Maguilla (1) } \\
\text { Sevilla (2) }\end{array}$ & Portugueses & Socios \\
\hline Francisco Rodríguez Lameira & Málaga (5) & Portugués & Factor \\
\hline $\begin{array}{l}\text { D. Martín de Arrese Girón, marqués de } \\
\text { Casares } \\
\text { [corregidor de Málaga] }\end{array}$ & Málaga (1) & Castellano & $\begin{array}{l}\text { Corresponsal } \\
\text { político }\end{array}$ \\
\hline D. Francisco de Medina Sotomayor & Mérida (4) & Castellano & - \\
\hline Francisco de Torres & Mérida (1) & Castellano & - \\
\hline Francisco Hernández Figueroa & Mérida (2) & Castellano & - \\
\hline Héctor López Portachón & Mérida (1) & Castellano & - \\
\hline Manuel Gómez de Fonseca & Mérida (2) & Portugués & Corresponsal \\
\hline Melchor de Barrasa & Plasencia (4) & - & Agente \\
\hline Manuel de Torres & $\begin{array}{l}\text { Plasencia (1) } \\
\text { Trujillo (1) }\end{array}$ & Portugués & Agente \\
\hline
\end{tabular}

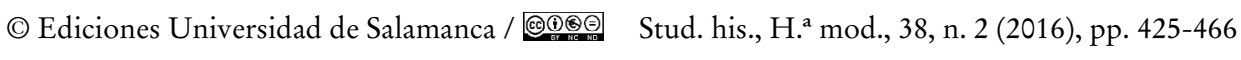


ÁLVARO SÁNCHEZ DURÁN

INFORMACIÓN Y REPUTACIÓN EN EL SIGLO XVII: LA CONSTRUCCIÓN DE LA CONFIANZA EN REDES SOCIALES DE HOMBRES DE NEGOCIOS PORTUGUESES

\begin{tabular}{|c|c|c|c|}
\hline $\begin{array}{l}\text { Remitente(s) } \\
\text { [en cursiva: parientes] }\end{array}$ & Origen $\left(\mathrm{y} \mathrm{n} .{ }^{\circ}\right)$ de cartas & Nación & Relación \\
\hline $\begin{array}{l}\text { Diego de Salvatierra y del Burgo } \\
\text { [regidor de Salamanca] }\end{array}$ & Salamanca (1) & Castellano & Agente \\
\hline Francisco de Beroiz Fagola & San Sebastián (1) & Vizcaíno & Agente \\
\hline Pedro Meléndez Ayones & Segovia (1) & Castellano & Agente \\
\hline Duarte de Espinosa & Sevilla (5) & $\begin{array}{l}\text { Portugués } \\
\text { (naturalizado } \\
\text { castellano) }\end{array}$ & Agente \\
\hline Alfonso Núñez Muñoz & Sevilla (3) & Portugués & Agente \\
\hline Antonio López Castrogago & Sevilla (1) & Portugués & Agente \\
\hline Diego Rodríguez Luis & Sevilla (1) & Portugués & Agente \\
\hline Simón Rodríguez Núñez & Sevilla (9) & Portugués & Factor \\
\hline Juan de Vezares & Sevilla (1) & Castellano & $\begin{array}{l}\text { Criado de } \\
\text { factor }\end{array}$ \\
\hline Manuel Núñez Mercado & Sevilla (1) & Portugués & Socio \\
\hline Manuel de Sosa Núñez & Sevilla (2) & Portugués & Agente \\
\hline Melchor Rodríguez Pardo & Sevilla (1) & Portugués & Corresponsal \\
\hline Diego Rodríguez de Asanbuja & Soria (1) & - & - \\
\hline Fernán Gómez Gil & Toledo (10) & Portugués & Agente \\
\hline Rodrigo Arias & Toledo (5) & - & Agente \\
\hline Gaspar Rodríguez Moreira & Toledo (1) & Portugués & - \\
\hline Manuel Rodríguez & $\begin{array}{l}\text { Trujillo (5) } \\
\text { Villanueva de la Serena } \\
(2)\end{array}$ & Portugués & Agente \\
\hline Cristóbal de Saboya & Valencia (1) & - & Corresponsal \\
\hline Bernardo de la Fuente & Valladolid (5) & Castellano & Agente \\
\hline Manuel Núñez Mercado (el mayor) & $\begin{array}{l}\text { Villanueva de la Serena } \\
\text { (10) }\end{array}$ & Portugués & Corresponsal \\
\hline
\end{tabular}

\section{Bibliografía}

Amelang, J. S.: The Flight of Icarus. Artisan Autobiography in Early Modern Europe. Stanford, 1998.

AntunEs, C.: «A história da análise de redes e a análise de redes em história», História. Revista da FLUP Porto, IV Série, vol. 2, 2012, pp. 11-22.

(C) Ediciones Universidad de Salamanca / @®@@ Stud. his., H. ${ }^{a}$ mod., 38, n. 2 (2016), pp. 425-466 
Aslanian, S.: From the Indian Ocean to the Mediterranean. The Global Trade Networks of Armenian Merchants from New Julfa. Berkeley-Los Ángeles, 2011.

BASKes, J.: «Communication Breakdown: Information and Risk in Spanish Atlantic World Trade during an Era of "Free Trade" and War», Colonial Latin American Review, vol. 20, 1, 2011, pp. 35-60.

Boyajian, J. C.: Portuguese Bankers at the Court of Spain, 1626-1650. New Brunswick-New Jersey, 1983.

Broens, N.: Monarquía y Capital Mercantil: Felipe IV y las Redes Comerciales Portuguesas (1627-1635). Madrid, 1989.

Calafat, G.: «Diasporas marchandes et commerce interculturel. Familles, réseaux et confiance dans l'economie de l'époque moderne», Annales. Histoire, Sciences Sociales, vol. 66, 2, pp. 513-531.

Coleman, J. S.: «Social Capital and the Creation of Human Capital», American Journal of Sociology, vol. 94, 1988, pp. S95-S120.

COURT, R.: «"Januensis Ergo Mercator": Trust and Enforcement in the Business Correspondence of the Brignole Family», The Sixteenth Century Journal, vol. 35, 4, 2004, pp. 987-1003.

Crespo Solana, A. (Ed.): Spatio-Temporal Narratives. Historical GIS and the Study of Global Trading Networks (1500-1800). Newcastle, 2014.

Cusin, F.: «Relations marchandes et esprit d'enterprise: La construction sociale de la confiance», Revue Interventions économiques, 33, 2006, pp. 2-23.

De Cruz Medina, M. V.: Cartas, Mujeres y Corte en el Siglo de Oro. Tesis doctoral inédita, Universidad Complutense de Madrid, 2010.

Del Lungo Camiciotтi, G.: «Letters and Letter Writing in Early Modern Culture: An Introduction», Journal of Early Modern Studies, 3, 2014, pp. 17-35.

Ebben, M. A.: «Corona y comerciantes: García de Yllán, un mercader al servicio de Felipe IV», Diálogos Hispánicos, vol. 16, 1995, pp. 169-186.

Edwards, J., y Ogilvie, S.: «Contract Enforcement, Institutions, and Social Capital: the Maghribi Traders Reappraised», Economic History Review, vol. 65, 2, 2012, pp. 421-444.

Elliott, J. H.: El conde-duque de Olivares. El político en una época de decadencia. Barcelona, 2004.

García Guerra, E. M.: «La moneda de vellón: un instrumento al servicio de la fiscalidad del Estado Moderno: las Cortes», Cuadernos de Historia Moderna, vol. 21, 1998, pp. 59-101.

Granovetter, M.: «The Strength of Weak Ties: A Network Theory Revisited», Sociological Theory, vol. 1, 1983, pp. 201-233.

Granovetter, M.: «Economic Action and Social Structure: The Problem of Embeddedness», The American Journal of Sociology, vol. 91, 3, 1985, pp. 481-510.

GreIF, A.: «Reputation and Coalitions in Medieval Trade: Evidence on the Maghribi Traders», The Journal of Economic History, vol. 49, 4, 1989, pp. 857-882.

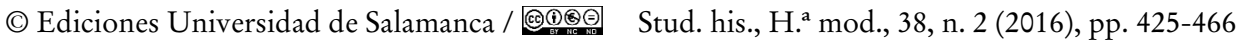


GreIF, A.: Institutions and the Path to the Modern Economy. Lessons from Medieval Trade. Nueva York, 2006.

Guinnane, T.: «Trust: A Concept too Many», Jabrbuch für Wirtschaftsgeschichte / Economic History Yearbook, vol. 46, 1, 2005, pp. 77-92.

Guinnane, T.: «Les économistes, le crédit et la confiance», Genèses, 79, 2010, pp. 6-25.

Imízcoz BeunZA, J. M.: «Actores, redes, procesos: reflexiones para una historia más global», História. Revista da FLUP Porto, III Série, vol. 5, 2004, pp. 115-140.

Imízcoz Beunza, J. M., y Arroyo Ruiz, L.: «Redes sociales y correspondencia epistolar. Del análisis cualitativo de las relaciones personales a la reconstrucción de redes personales», REDES. Revista hispana para el análisis de redes sociales, vol. 21, 4, 2011, pp. 98-138.

Israel, J. I.: «Spanish Wool Exports and the European Economy, 1610-40», The Economic History Review, New Series, vol. 33, 2, 1980, pp. 193-211.

Israel, J. I.: Empires and Entrepots. The Dutch, the Spanish Monarchy and the Jerws, 15851713. Londres-Ronceverte, 1990.

LAmikiz, X.: «Un «cuento ruidoso»: Confidencialidad, reputación y confianza en el comercio del siglo XVIII", Obradoiro de Historia Moderna, 16, 2007, pp. 113-142.

Lamikiz, X.: Trade and Trust in the Eighteenth-Century Atlantic World. Spanish Merchants and their Overseas Networks. Londres-Woodbridge, 2010.

LEMERCIER, C.: «Analyse de réseaux et histoire», Revue d'histoire moderne et contemporaine, 52/2, 2005, pp. 88-112.

López Belinchón, B. J.: Honra, libertad y hacienda. Hombres de negocios y judios sefardies. Alcalá de Henares, 2001.

López Belinchón, B. J.: ««Sacar la sustancia al Reino». Comercio, contrabando y conversos portugueses, 1621-1640», Hispania. Revista Española de Historia, LXI/3, 209, 2001, pp. 1017-1050.

Mathias, P.: «Risk, Credit and Kinship in Early Modern Enterprise», en McCusker, J. J. y Morgan, K. (Eds.): The Early Modern Economy. Cambridge, 2000, pp. 15-35.

McLean, P. D.: The Art of the Network. Strategic Interaction and Patronage in Renaissance Florence. Durham-Londres, 2007.

Moutoukias, Z.: «Negocios y redes sociales: modelo interpretativo a partir de un caso rioplatense (Siglo XVIII)», Caravelle, 67, 1997, pp. 37-55.

Muldrew, C.: The Economy of Obligation. The Culture of Credit and Social Relations in Early Modern England. Londres, 1998.

NorTh, D. C.: Institutions, Institutional Change, and Economic Performance. Cambridge, 1990.

OgILVIE, S.: «The Use and Abuse of Trust: Social Capital and its Deployment by Early Modern Guilds», Jabrbuch für Wirtschaftsgeschichte / Economic History Yearbook, vol. 46, 1, 2005, pp. 15-52.

Ribeiro, A. S.: Mechanism and Criteria of Cooperation in Trading Networks of the First Global Age. The Case Study of Simón Ruiz Network, 1557-1597. Tesis doctoral inédita, Universidad de Oporto, 2011.

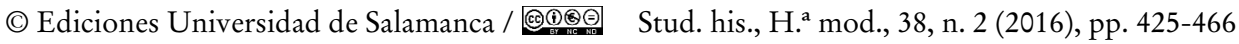


Ribeiro, A. S.: «Letras de câmbio e correspondencia comercial como materiais da história. O acto de cooperar sob olhares distintos», CEM Cultura, Espaço E Memória: Revista do CITCEM, 2, 2011, pp. 159-169.

Ribeiro, A. S.: «A endogamia em redes mercantis da «Primeira Idade Global». O caso da rede de Simon Ruiz (1553-1597)», História. Revista da FLUP Porto, IV Série, vol. 2, 2012, pp. 23-40.

SÁnchez Durán, A.: «Los hombres de negocios portugueses: una élite profesional en la Castilla del siglo Xvir. Posibilidades de movilidad social e intermediación», Tiempos Modernos. Revista electrónica de Historia Moderna, vol. 8, 31, 2015, pp. 193-220.

SAnz Ayán, C.: Los banqueros de Carlos II. Valladolid, 1988.

SANZ AyÁN, C.: «Procedimientos culturales y transculturales de integración en un clan financiero internacional: los Cortizos (siglos XVII y XVIII)», en Yun Casalilla, B. (Dir.): Las redes del imperio. Élites sociales en la articulación de la Monarquia Hispánica, 1492-1714. Madrid, 2009, pp. 65-94.

SANZ Ayán, C.: Los banqueros y la crisis de la Monarquía Hispánica de 1640. Madrid, 2013.

SAnZ Ayán, C.: Un banquero en el siglo de oro. Octavio Centurión, el financiero de los Austrias. Madrid, 2015.

SMAIL, J.: «Credit, Risk and Honor in Eighteenth-Century Commerce», Journal of British Studies, vol. 44, 3, 2005, pp. 439-456, https://doi.org/10.1086/429706.

STRum, D.: The Sugar Trade. Brazil, Portugal, and the Netherlands (1595-1630). Stanford, 2013.

Studnicki-Gizbert, D.: A Nation Upon the Ocean Sea. Portugal's Atlantic Diaspora and the Crisis of the Spanish Empire, 1492-1640. Nueva York, 2007.

Trivellato, F.: «Juifs de Livourne, Italiens de Lisbonne, hindous de Goa. Réseaux marchands et échanges interculturels à l'époque moderne», Annales. Histoire, Sciences Sociales, vol. 58, 3, 2003, pp. 581-603.

Trivellato, F.: The Familiarity of Strangers. The Sephardic Diaspora, Livorno and CrossCultural Trade in the Early Modern Period. New Haven-Londres, 2009.

VAnNeste, T.: Global Trade and Commercial Networks: Eighteenth-Century Diamond Merchants. Londres, 2011.

Williamson, O. E.: «Calculativeness, Trust, and Economic Organization», The Journal of Law E Economics, vol. 36, 1, 1993, pp. 453-486, https://doi.org/10.1086/467284.

(C) Ediciones Universidad de Salamanca / @®@@ Stud. his., H. ${ }^{a}$ mod., 38, n. 2 (2016), pp. 425-466 